Article

\title{
Network Pharmacology of Red Ginseng (Part I): Effects of Ginsenoside Rg5 at Physiological and Sub-Physiological Concentrations
}

\author{
Alexander Panossian 1,*(D), Sara Abdelfatah ${ }^{2}$ (D) and Thomas Efferth ${ }^{2, *}$ \\ 1 EuroPharma USA Inc., Green Bay, WI 54311, USA \\ 2 Department of Pharmaceutical Biology, Institute of Pharmaceutical and Biomedical Sciences, Johannes \\ Gutenberg University, 55131 Mainz, Germany; saabdelf@uni-mainz.de \\ * Correspondence: ap@phytomed.se (A.P.); efferth@uni-mainz.de (T.E.)
}

Citation: Panossian, A.; Abdelfatah, S.; Efferth, T. Network Pharmacology of Red Ginseng (Part I): Effects of Ginsenoside Rg5 at Physiological and Sub-Physiological Concentrations. Pharmaceuticals 2021, 14, 999. https://doi.org/10.3390/ph14100999

Academic Editor: Daniela De Vita

Received: 14 September 2021

Accepted: 27 September 2021

Published: 29 September 2021

Publisher's Note: MDPI stays neutral with regard to jurisdictional claims in published maps and institutional affiliations.

Copyright: (c) 2021 by the authors. Licensee MDPI, Basel, Switzerland. This article is an open access article distributed under the terms and conditions of the Creative Commons Attribution (CC BY) license (https:// creativecommons.org/licenses/by/ $4.0 /)$.

\begin{abstract}
Numerous in vitro studies on isolated cells have been conducted to uncover the molecular mechanisms of action of Panax ginseng Meyer root extracts and purified ginsenosides. However, the concentrations of ginsenosides and the extracts used in these studies were much higher than those detected in pharmacokinetic studies in humans and animals orally administered with ginseng preparations at therapeutic doses. Our study aimed to assess: (a) the effects of ginsenoside Rg5, the major "rare" ginsenoside of Red Ginseng, on gene expression in the murine neuronal cell line HT22 in a wide range of concentrations, from $10^{-4}$ to $10^{-18} \mathrm{M}$, and (b) the effects of differentially expressed genes on cellular and physiological functions in organismal disorders and diseases. Gene expression profiling was performed by transcriptome-wide mRNA microarray analyses in HT22 cells after treatment with ginsenoside Rg5. Ginsenoside Rg5 exhibits soft-acting effects on gene expression of neuronal cells in a wide range of physiological concentrations and strong reversal impact at high (toxic) concentration: significant up- or downregulation of expression of about 300 genes at concentrations from $10^{-6} \mathrm{M}$ to $10^{-18} \mathrm{M}$, and dramatically increased both the number of differentially expressed target genes (up to 1670) and the extent of their expression (fold changes compared to unexposed cells) at a toxic concentration of $10^{-4} \mathrm{M}$. Network pharmacology analyses of genes' expression profiles using ingenuity pathway analysis (IPA) software showed that at low physiological concentrations, ginsenoside Rg5 has the potential to activate the biosynthesis of cholesterol and to exhibit predictable effects in senescence, neuroinflammation, apoptosis, and immune response, suggesting soft-acting, beneficial effects on organismal death, movement disorders, and cancer.
\end{abstract}

Keywords: red ginseng; ginsenoside Rg5; gene expression; IPA pathways; network pharmacology; transcriptomics

\section{Introduction}

The Panax ginseng Meyer root has been traditionally used in China, Korea, and Japan for thousands of years for many conditions, including the age-related decline of cognitive function, general weakness, and enhancing longevity [1-7]. In Europe, ginseng preparations are recognized as a general tonic or adaptogen in cases of fatigue, weakness, and decreased mental and physical capacity at daily doses equivalent to 600-2000 mg of powdered herbal substance [3,4]. The results of many clinical trials suggesting the beneficial effects of ginseng on stress and cognitive functions were critically reviewed in several comprehensive and systematic review articles [3,8-14]. Overall, ginseng is a promising treatment for mental, industrial, and chronic fatigue [15-19], and for the cognitive enhancement performance of healthy subjects [6,19-24], and patients with mild cognitive impairments [25-31] and/or neurological disorders [7,26-28].

Numerous in vitro studies on isolated cells have been conducted to uncover the molecular mechanisms of action of ginseng extracts and isolated ginsenosides (Supple- 
mental Table S1 in Supplement 1). However, the concentrations of ginsenosides and the extracts used in these studies [32-43] were incompatibly higher than those detected in pharmacokinetic (PK) studies in humans $[44,45]$ and animals orally administrated with ginseng preparations at the highest therapeutic doses [46-51] (Supplemental Table S2 in Supplement 1).

As an example, ginsenoside Rg5, the major ginsenoside of Red Ginseng, was tested in vitro (Supplemental Table S2 in Supplement 1) mainly in the concentration range from 20 to $100 \mu \mathrm{M}$, while the maximal concentration of Rg5 was 2-10 nM (about 2000-fold lower) in the blood of human subjects taking ginseng orally at a dose of $9 \mathrm{~g}$ [44] (Supplemental Table S2 in Supplement 1). The maximal concentration of Rg5 was only $81 \mathrm{nM}$ [48] (203300 -fold lower) in the blood of dogs after orally administered ginseng at a dose of $5 \mathrm{~g}$ (corresponding human dose: $39 \mathrm{~g}$ ). These discrepancies/inconsistencies raise the question about the clinical relevance of results obtained from in vitro models (where substantially higher concentrations were used) and the pharmacological activity of ginsenosides and their metabolites in nano-molar concentrations detected in animal blood and human subjects.

To the best of our knowledge, the only in vitro study where the pharmacological activity of ginsenosides had been tested at nano-molar concentrations was the study, where in ginsenosides Rg5, Rb1, and Rc protected neurons from glutamate-induced apoptosis in vitro in Huntington's disease (HD) assay at concentrations of 1000, 100 and 10 nM, respectively [32]. Ginsenosides $\mathrm{Rd}, \mathrm{Re}, \mathrm{Rg} 3, \mathrm{Rh} 1, \mathrm{Re}, \mathrm{Rd}, \mathrm{Rk} 1, \mathrm{Rh} 4$, and $\mathrm{Rk} 3$ were inactive or exerted toxic effects [32]. Ginsenoside Rg5 was toxic at concentrations from 78 to $104 \mu \mathrm{M}$ in experiments with murine hippocampal HT22 cells and exhibited a neuroprotective effect in heat stress-induced apoptosis [33]. The lower concentrations have not been studied in in vitro experiments even though ginsenosides and their metabolites were detected at nanomolar concentrations in the circulating blood system of human subjects (Supplemental Table S2 in Supplement 1). Furthermore, levels of brain hormones might not be the same as those in the blood, as it has been reported for estrogens that levels in the brain were $0.08-0.19 \mathrm{ng} / \mathrm{g}$ wet weight [52].

Our study aimed to assess: (a) the effects of ginsenoside Rg5, the major "rare" ginsenoside of Red Ginseng, on gene expression in the murine neuronal cell line HT22 in a wide range of concentrations from $10^{-4}$ to $10^{-8} \mathrm{M}$, and (b) the effects of differentially expressed genes on cellular and physiological functions in organismal disorders and diseases.

\section{Results}

2.1. Effect of Ginsenoside Rg5 on Gene Expression Profiles in the Murine Hippocampal Neuronal Cell Line HT22

Table 1 and Figure 1 a show that the total number of genes deregulated by ginsenoside $\operatorname{Rg} 5$ in a concentration range from $1 \mu \mathrm{M}$ to $1 \mathrm{aM}$ is roughly the same-370 \pm 69 $(\mathrm{RSD}=18.53 \%)$, while at a toxic concentration of $100 \mu \mathrm{M} \operatorname{Rg} 5$ differentially regulated 1670 genes ( 4.5-fold more). A majority (73\%) of these genes (1215 of 1670) were uniquely differentially regulated by $\operatorname{Rg} 5$ only at this toxic concentration of $100 \mu \mathrm{M}$.

The effect size of gene expression was in a range from 300 to 800-fold change compared to their expression in control cells unexposed to Rg5 at all tested concentrations except the highest toxic concentration of $100 \mu \mathrm{M}$. In the latter case, the gene expression was increasing up to 2600-fold, particularly of genes which were not deregulated at lower concentrations (Supplemental Table S3a in Supplement 2).

At the highest (toxic) concentration, Rg5 dramatically increased the fold change of many genes in a dose-response reversal manner (Figure 1b), a common phenomenon known as hormesis. That was in line with other observations, where ginsenosides, including Rg5, exhibited hormetic response in various in vitro and in vivo studies [53]. 
Table 1. Number of genes deregulated ${ }^{1}$ by ginsenoside Rg5 in different concentrations in the murine hippocampal neuronal cell line HT22. For details, see Supplemental Table S3 in Supplement 2.

\begin{tabular}{cccccc}
\hline Sample Name & $\begin{array}{c}\text { Rg5 } \\
\text { Concentration }\end{array}$ & $\begin{array}{c}\text { Molecules of } \\
\text { Rg5 per Cells, } \\
\text { Ratio }\end{array}$ & $\begin{array}{c}\text { Number of } \\
\text { Deregulated } \\
\text { Genes }\end{array}$ & $\begin{array}{c}\text { Number of } \\
\text { Deregulated } \\
\text { Genes Unique } \\
\text { Only in } \\
\text { Selected Conc. }\end{array}$ & $\begin{array}{c}\text { Fold Changes of } \\
\text { the Only Gene, } \\
\text { Ca6, Which is } \\
\text { Deregulated in } \\
\text { All Conc. }\end{array}$ \\
\hline S2 & $10^{-4} \mathrm{M}$ & $12 \times 10^{11}$ & 1670 & 1215 & 731 \\
$\mathrm{~S} 3$ & $10^{-6} \mathrm{M}$ & $12 \times 10^{9}$ & 280 & 120 & -306 \\
S4 & $10^{-9} \mathrm{M}$ & $12 \times 10^{6}$ & 328 & 122 & -286 \\
S5 & $10^{-12} \mathrm{M}$ & $12 \times 10^{3}$ & 380 & 163 & -274 \\
$\mathrm{~S} 6$ & $10^{-15} \mathrm{M}$ & 12 & 471 & 252 & -281 \\
$\mathrm{~S} 7$ & $10^{-17} \mathrm{M}$ & $2: 10^{2}$ & 343 & 159 & -293 \\
$\mathrm{~S} 8$ & $10^{-18} \mathrm{M}$ & $2: 10^{3}$ & 422 & 178 & -313 \\
\hline
\end{tabular}

${ }^{1}>20$-fold compared to control.

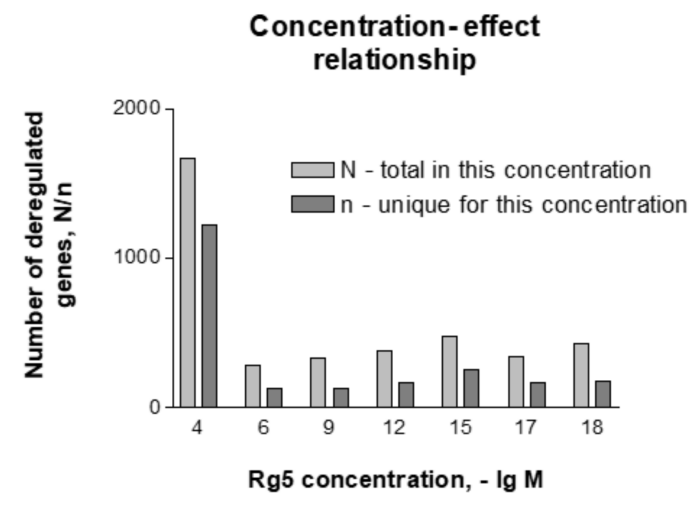

(a)

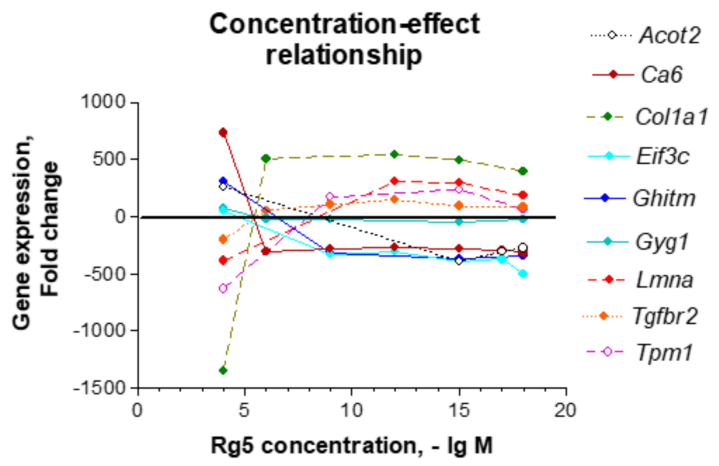

(b)

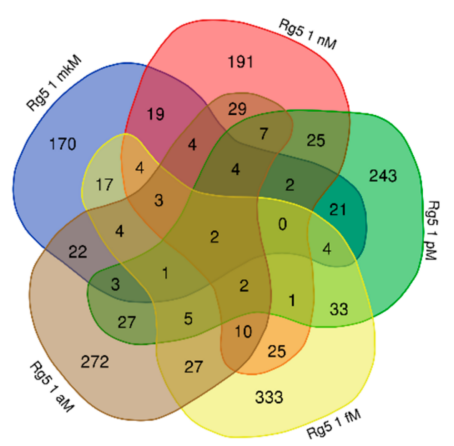

(c)

Figure 1. (a) The total number of genes deregulated by ginsenoside $\operatorname{Rg} 5$ in concentrations ranging from $1 \mu \mathrm{M}$ to 1 aM; (b) ginsenoside $\operatorname{Rg} 5$ concentration-dependent fold change expression of selected differentially regulated genes in the hippocampal neuronal cell line HT22; (c) Venn diagram of genes deregulated by ginsenoside Rg5 at concentrations $1 \mu \mathrm{M}$, $1 \mathrm{nM}, 1 \mathrm{pM}, 1 \mathrm{gM}$ and $1 \mathrm{aM}$.

Only nine of 2897 differentially regulated genes (Supplemental Table S3 in Supplement 2), were commonly deregulated by ginsenoside $\operatorname{Rg} 5$ at five or more tested concentrations (Ca6, Cth, Col1a1, Dipk2a, Eif3c, Enox2, Gyg1, Tgfbr2 and 1700001F09Rik), and only two genes (Ca6 and Tgfbr2) at concentrations from $1 \mu \mathrm{M}$ to 1 aM (Figure 1c, and Tables S3b-e,g in Supplement 2). 
Only one gene, Ca6 encoding extracellular enzyme carbonic anhydrase 6, was differentially regulated in all tested concentrations (Table 1), but in a reversed manner: upregulation at the highest $100 \mu \mathrm{M}$ concentration, and downregulation at all other concentrations of $\operatorname{Rg} 5$.

These observations suggest that Rg5 was pharmacologically active in a wide range of concentrations of neuronal cells from $10^{-6} \mathrm{M}$ to $10^{-18} \mathrm{M}$ (Figure $1 \mathrm{c}$ ) and had a significant impact on the gene expression of hippocampal neurons.

\subsection{Effect of Ginsenoside Rg5 on Signaling Canonical Pathways}

In Figures $2-5$ the effect $(-\log p$-value $>1.3, z$-score $>2)$ of various concentrations of ginsenoside Rg5 on deregulated intracellular signaling canonical pathways are presented: neurotransmitters and nervous system signaling (including neuroinflammation, and CREB signaling in neurons) (Figure 2); cellular immune response, stress and injury signaling (including senescence and EIF2 signaling) (Figure 3); nuclear receptors and transcriptional regulation signaling (including estrogen receptors and sirtuin signaling) (Figure 4); apoptosis and cancer (including death receptors, PD-1 cancer immunotherapy, and tumor microenvironment signaling) canonical pathways (Figure 5).

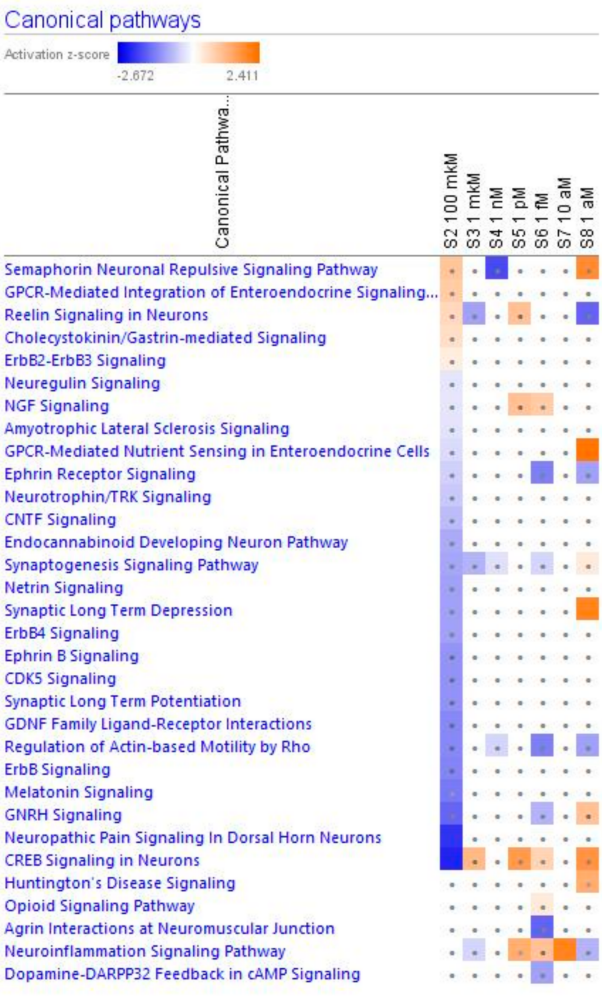

(a)

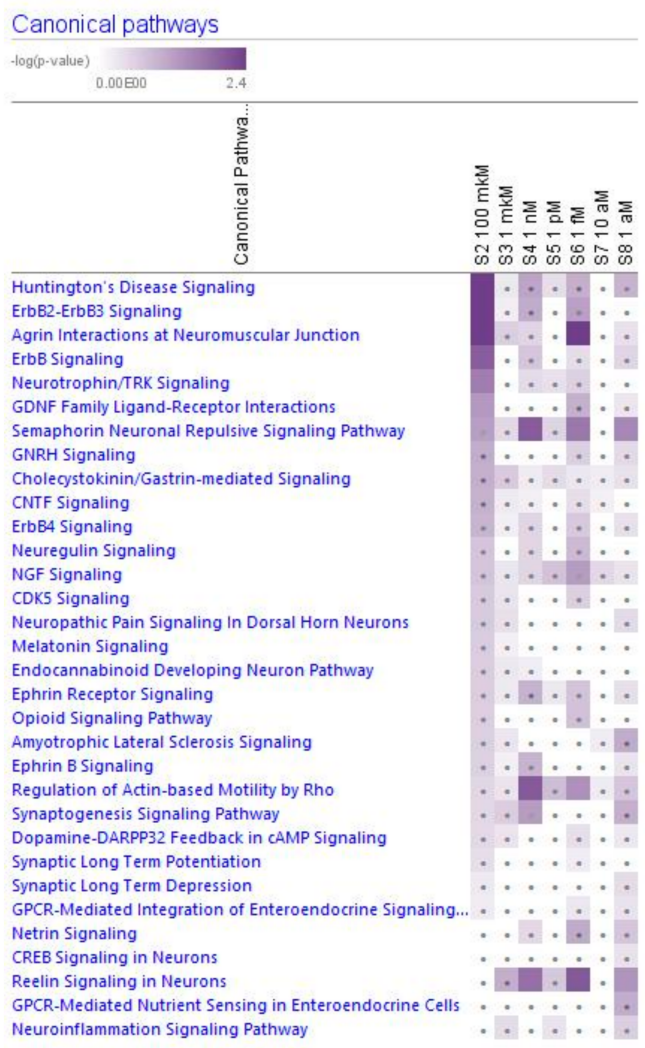

(b)

Figure 2. Effect of Rg5 in concentrations of $1 \mathrm{aM}, 10 \mathrm{aM}, 1 \mathrm{fM}, 1 \mathrm{pM}, 1 \mathrm{nM}, 1 \mu \mathrm{M}$ and $100 \mu \mathrm{M}$ ) on neurotransmitters and nervous system signaling. (a) Brown color depicts predicted activation, blue color-predicted inhibition of signaling pathway; symbol shows that the activation $z$-score was $<2$. (b) Symbol shows that the $-\log p$-value was $<1.3$. 


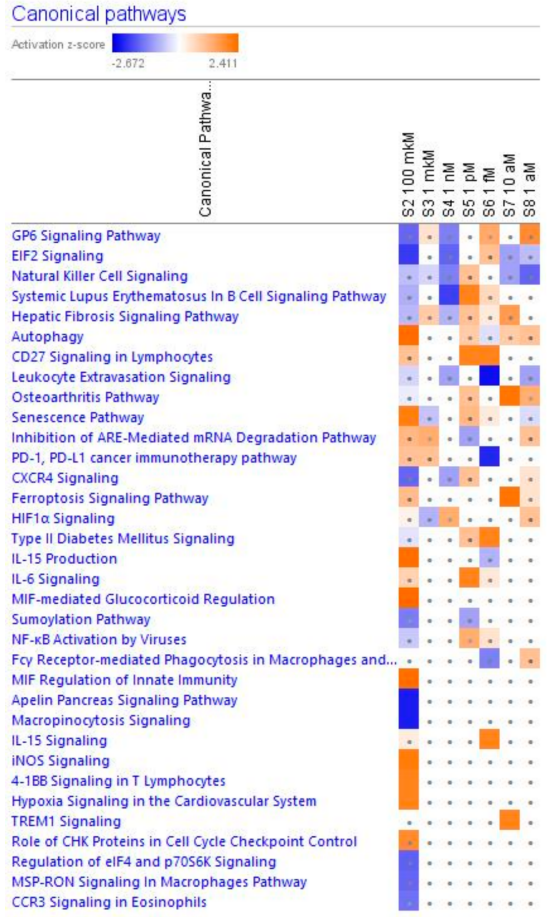

(a)

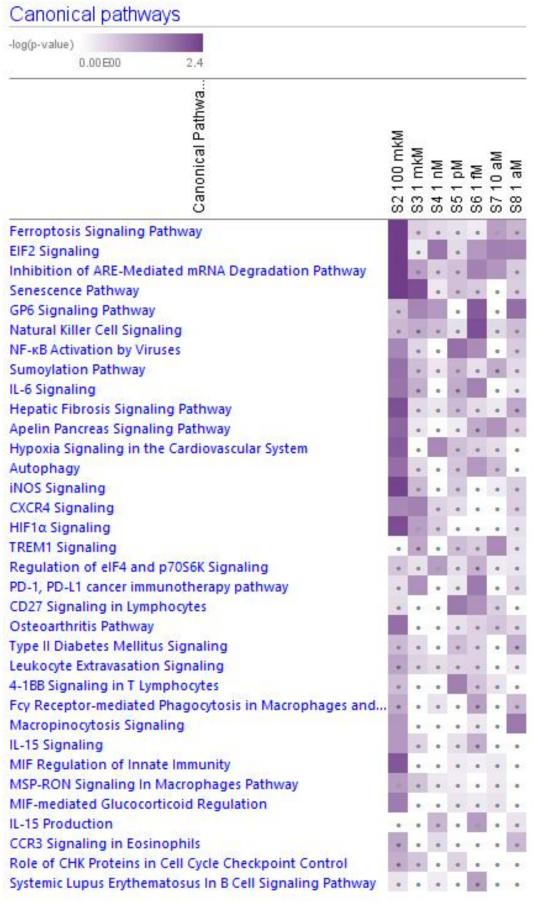

(b)

Figure 3. Effect of Rg5 in concentrations of $1 \mathrm{aM}, 10 \mathrm{aM}, 1 \mathrm{fM}, 1 \mathrm{pM}, 1 \mathrm{nM}, 1 \mu \mathrm{M}$ and $100 \mu \mathrm{M})$ on cellular immune response, stress and injury (including senescence and EIF2 signaling) signaling. (a) The brown color depicts predicted activation, blue color-predicted inhibition of signaling pathway; the symbol shows that the activation $z$-score was $<2$. (b) the symbol shows that the $-\log p$-value was $<1$.3.

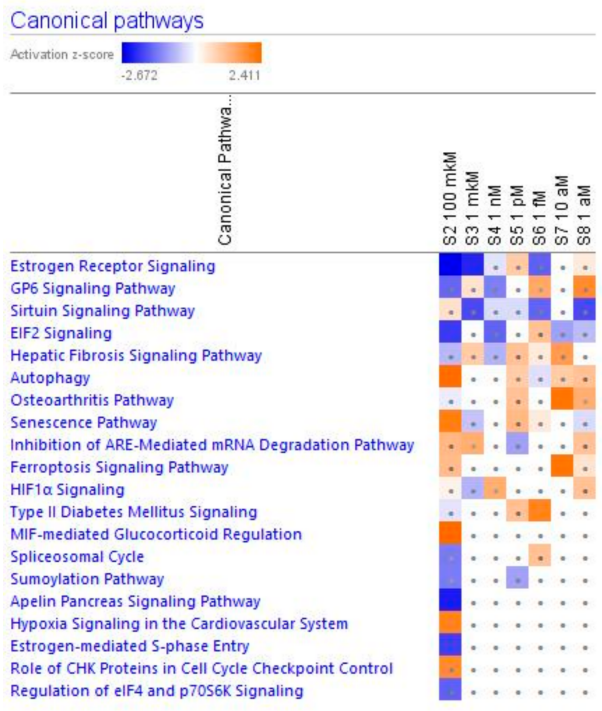

(a)

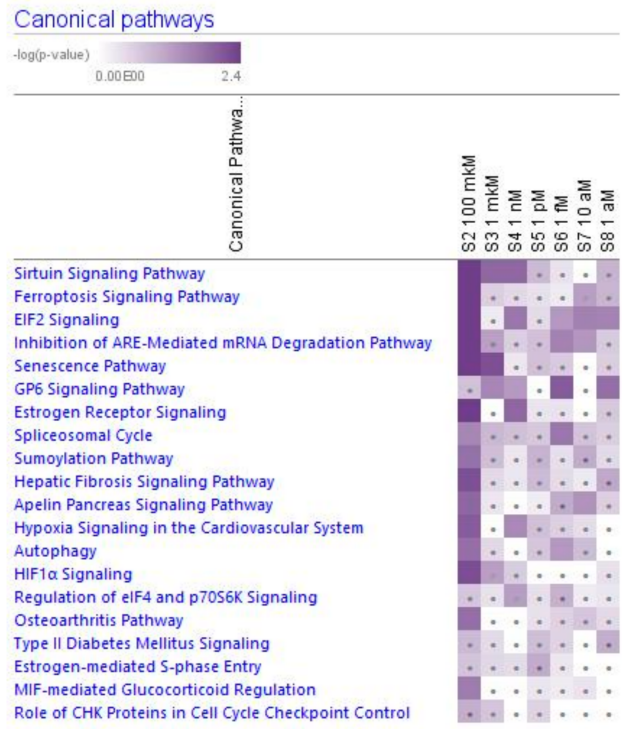

(b)

Figure 4. Effect of Rg5 in concentrations of $1 \mathrm{aM}, 10 \mathrm{aM}, 1 \mathrm{fM}, 1 \mathrm{pM}, 1 \mathrm{nM}, 1 \mu \mathrm{M}$ and $100 \mu \mathrm{M})$ on nuclear receptors and transcriptional regulation (including estrogen receptors and sirtuin) signaling. (a) The brown color depicts predicted activation, blue color-predicted inhibition of signaling pathway; the symbol shows that the activation z-score was $<2$. (b) The symbol shows that the $-\log$ $p$-value was $<1.3$. 
Canonical pathways

Activation z-score
Autophagy
IL-15 Production
Endocannabinoid Cancer Inhibition Pathway
Senescence Pathway
Hypoxia Signaling in the Cardiovascular System
Role of CHK Proteins in Cell Cycle Checkpoint Control
HER-2 Signaling in Breast Cancer
Inhibition of ARE-Mediated mRNA Degradation Pathway
Ferroptosis Signaling Pathway
PD-1, PD-L1 cancer immunotherapy pathway
CD27 Signaling in Lymphocytes
IL-15 Signaling
HIF1a Signaling
Osteoarthritis Pathway
Type II Diabetes Mellitus Signaling
Hepatic Fibrosis Signaling Pathway
Induction of Apoptosis by HIV1
Glioblastoma Multiforme Signaling
Ovarian Cancer Signaling
Melanoma Signaling
Death Receptor Signaling
Acute Myeloid Leukemia Signaling
GP6 Signaling Pathway
Thyroid Cancer Signaling
Endometrial Cancer Signaling
Regulation of elF4 and p70s6K Signaling
ElF2 Signaling
Glioma Signaling
Apelin Pancreas Signaling Pathway
PTEN Signaling
HOTAIR Regulatory Pathway
Colorectal Cancer Metastasis Signaling
Tumor Microenvironment Pathway

Canonical pathways

\begin{tabular}{l} 
log(p-value) \\
\hline D.00E00 \\
Ferroptosis Signaling Pathway \\
HER-2 Signaling in Breast Cancer \\
Senescence Pathway \\
Tumor Microenvironment Pathway \\
EIF2 Signaling \\
Ovarian Cancer Signaling \\
Inhibition of ARE-Mediated mRNA Degradation Pathway \\
Glioma Signaling \\
Thyroid Cancer Signaling \\
HIF1a Signaling \\
Hepatic Fibrosis Signaling Pathway \\
Hypoxia Signaling in the Cardiovascular System \\
Apelin Pancreas Signaling Pathway \\
Endocannabinoid Cancer Inhibition Pathway \\
Osteoarthritis Pathway \\
Autophagy \\
Colorectal Cancer Metastasis Signaling \\
Acute Myyeloid Leukemia Signaling \\
IL-15 Signaling \\
Melanoma Signaling \\
Endometrial Cancer Signaling \\
PTEN Signaling \\
Role of CHK Proteins in Cell Cycle Checkpoint Control \\
Glioblastoma Multiforme Signaling \\
Type II Diabetes Mellitus Signaling \\
GP6 Signaling Pathway \\
HOTAIR Regulatory Pathway \\
Regulation of elF4 and p7056K Signaling \\
CD27 Signaling in Lymphocytes \\
PD-1, PD-L1 cancer immunotherapy pathway \\
Induction of Apoptosis by HIV1 \\
Death Receptor Signaling \\
IL-15 Production
\end{tabular}

(a)

(b)

Figure 5. Effect of Rg5 in concentrations of $1 \mathrm{aM}, 10 \mathrm{aM}, 1 \mathrm{fM}, 1 \mathrm{pM}, 1 \mathrm{nM}, 1 \mu \mathrm{M}$ and $100 \mu \mathrm{M}$ ) on apoptosis and cancer (including death receptor signaling, programmed death PD-1 cancer immunotherapy and tumor microenvironment) canonical pathways. (a) Brown color depicts predicted activation, blue color-predicted inhibition of signaling pathway; symbol shows that the activation z-score was $<2$. (b) Symbol shows that the $-\log p$-value was $<1.3$.

\subsubsection{Neurotransmitters and Nervous System Signaling}

The Neuroinflammation Signaling Pathway

The effect of ginsenoside Rg5 in all tested concentrations ( $1 \mathrm{aM}, 10 \mathrm{aM}, 1 \mathrm{fM}, 1 \mathrm{pM}$, $1 \mathrm{nM}, 1 \mu \mathrm{M}$, and $100 \mu \mathrm{M})$ on gene expression involved in the neuroinflammation signaling pathway is shown in Figure 6a.

Figure $6 \mathrm{~b}, \mathrm{c}$ present the predicted activation and inhibition of the pathway at concentrations of $100 \mu \mathrm{M}$ and $1 \mu \mathrm{M} \operatorname{Rg} 5$, respectively. The effects of $\operatorname{Rg} 5$ at all other tested concentrations are included in Supplement 3 in detail.

Table 2 demonstrates some primary endpoints of the neuroinflammation signaling pathway and the number of genes matching the pathway for predicting positive $(+)$ or negative (-) effects of $\operatorname{Rg} 5$ in various diseases and cellular processes associated with neuroinflammation. 
Canonical pathways

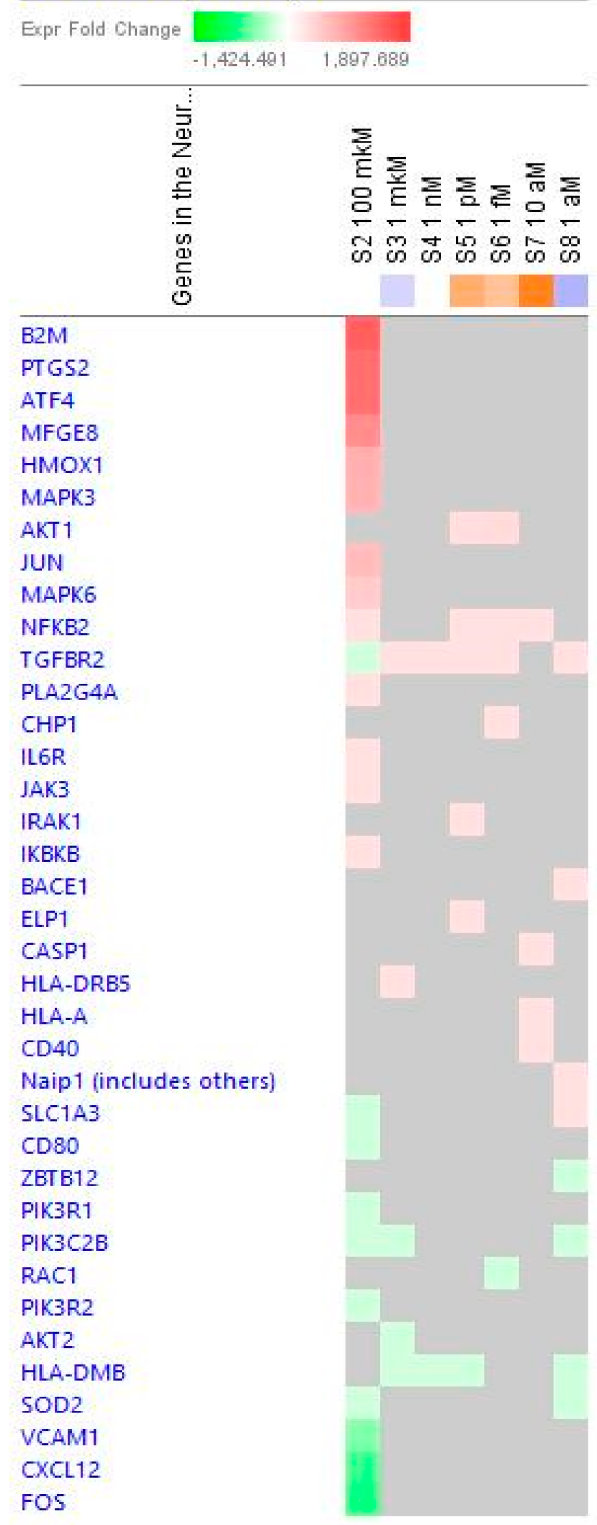

(a)

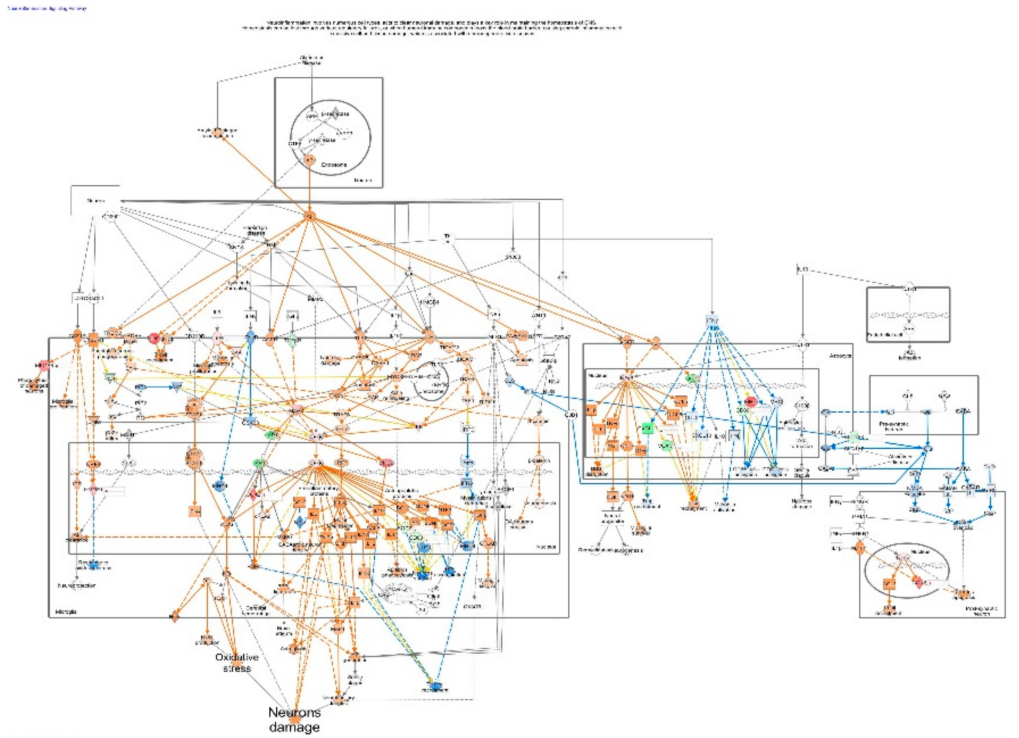

(b)

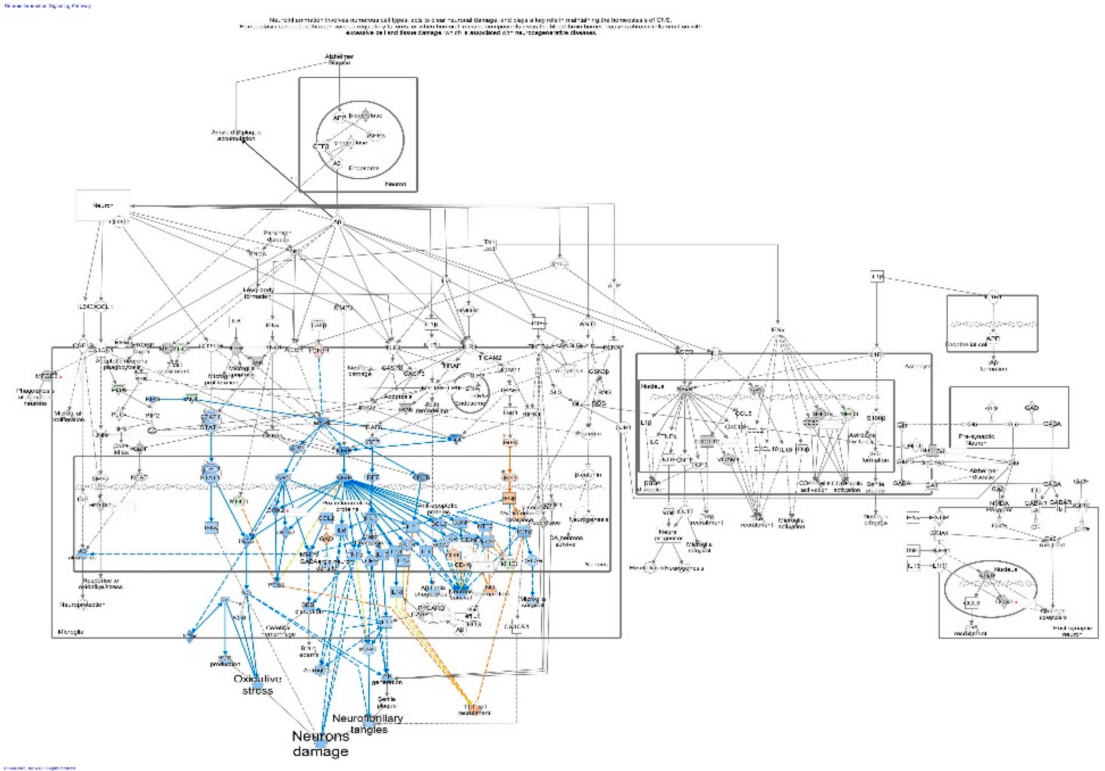

(c)

Figure 6. Effect of Rg5 on neuroinflammation signaling pathway: (a) Heatmap of gene expression (in fold changes compared to control, red, upregulation and green, downregulation), after exposure with ginsenoside Rg5 at different concentrations; the $100 \mu \mathrm{M}$ signature is shown in the leftmost column as solid red or green squares indicating genes that are upregulated or downregulated, respectively; color intensity indicates the actual log-fold changes; (b) Rg5 in the concentration of $100 \mu \mathrm{M}$ - predicted inhibition (blue) and activation (brown); (c) Rg5 at a concentration of $1 \mu \mathrm{M}$-predicted inhibition (blue) and activation (brown). 
Table 2. The number of genes matching neuroinflammation signaling pathway and predicted effects of Rg5 in various diseases and cellular processes associated with neuroinflammation ${ }^{1}$.

\begin{tabular}{|c|c|c|c|c|c|c|c|c|}
\hline Concentration of $\operatorname{Rg} 5, \mathrm{M}$ & & $10^{-4}$ & $10^{-6}$ & $10^{-9}$ & $10^{-12}$ & $10^{-15}$ & $10^{-17}$ & $10^{-18}$ \\
\hline No. of matching genes & & 23 & 5 & 2 & 6 & 5 & 4 & 8 \\
\hline Amyloid- $\beta$ plaque accumulation & disease & + & 0 & - & - & 0 & + & - \\
\hline Astrogliosis & disease & + & - & + & + & + & + & - \\
\hline $\mathrm{A} \beta$ formation/generation & disease & + & - & + & + & + & + & + \\
\hline Blood-brain barrier disruption & disease & + & - & $+/-$ & + & + & + & - \\
\hline Major depression & disease & + & - & + & + & + & + & - \\
\hline Oxidative stress & disease & + & - & - & + & - & + & - \\
\hline Neuron's damage & disease & + & - & + & + & + & + & - \\
\hline Neuron's survival & process & - & - & + & + & + & + & + \\
\hline Neuron's apoptosis & process & + & 0 & - & -+ & + & + & +- \\
\hline Th1 cell recruitment & process & - & + & - & - & - & - & + \\
\hline $\mathrm{T}$ cell recruitment & process & + & 0 & - & + & + & + & - \\
\hline GABAergic neuron density & process & + & - & + & + & + & + & - \\
\hline Amyloid- $\beta$ precursor protein & protein & + & 0 & - & - & 0 & + & - \\
\hline
\end{tabular}

${ }^{1} 0$-no effect; (+)—activation, (-)-inhibition compared to control.

It is noteworthy that $\operatorname{Rg} 5$ likely inhibits the neuronal damage, amyloid $\beta$ clearance and plague accumulation, blood-brain barrier disruption, major depression, and reactive oxygen species production both in acto-molar $\left(10^{-18} \mathrm{M}\right)$ and micromolar $\left(10^{-6} \mathrm{M}\right)$ concentrations, and induced reversal effect in the highest toxic concentration $\left(10^{-4} \mathrm{M}\right)$.

The cAMP/CREB Signaling Pathway in Neurons

The effect of ginsenoside Rg5 in all tested concentrations ( $1 \mathrm{aM}, 10 \mathrm{aM}, 1 \mathrm{fM}, 1 \mathrm{pM}$, $1 \mathrm{nM}, 1 \mu \mathrm{M}$ and $100 \mu \mathrm{M}$ ) on gene expression involved in cAMP/CREB signaling pathway is shown in Figure $7 \mathrm{a}$. Figure $7 \mathrm{~b}, \mathrm{c}$ present the predicted activation and inhibition of the pathway at concentrations $100 \mu \mathrm{M}$ and $1 \mu \mathrm{M} \operatorname{Rg} 5$, respectively. The effects of Rg5 on CREB signaling pathway gene expression at all other tested concentrations are included in Supplement 4 in detail.

\subsubsection{Cellular Immune Response, Cellular stress and Injury Signaling}

\section{Senescence}

The effect of ginsenoside Rg5 at all tested concentrations ( $1 \mathrm{aM}, 10 \mathrm{aM}, 1 \mathrm{fM}, 1 \mathrm{pM}$, $1 \mathrm{nM}, 1 \mu \mathrm{M}$ and $100 \mu \mathrm{M}$ ) on gene expression involved in the senescence signaling pathway is shown in Figure 8a. Figure 8b,c present the predicted activation and inhibition of the pathway at concentrations $100 \mu \mathrm{M}$ and $1 \mu \mathrm{M} \operatorname{Rg} 5$, respectively. The effects of $\operatorname{Rg} 5$ at all other tested concentrations are included in Supplement 5 in detail. 


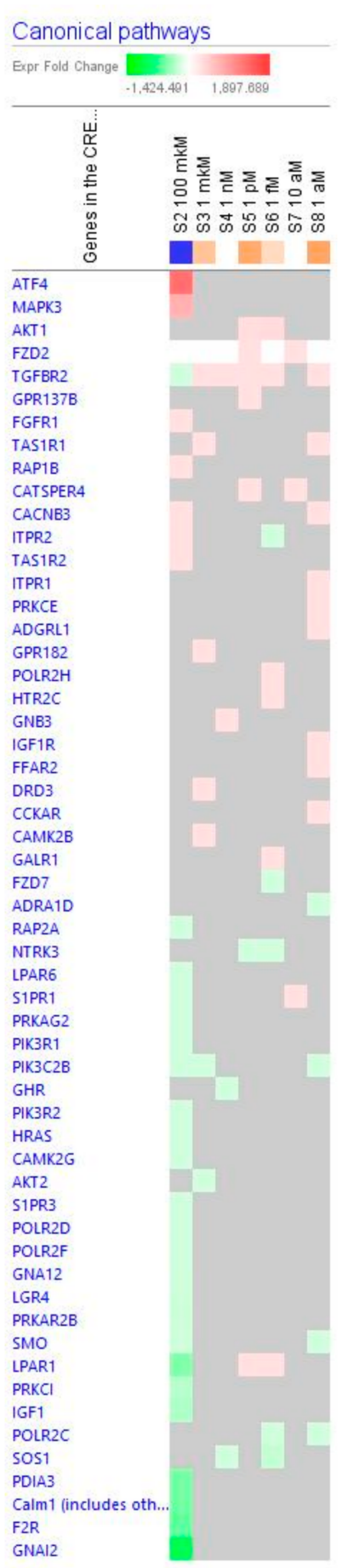

(a)

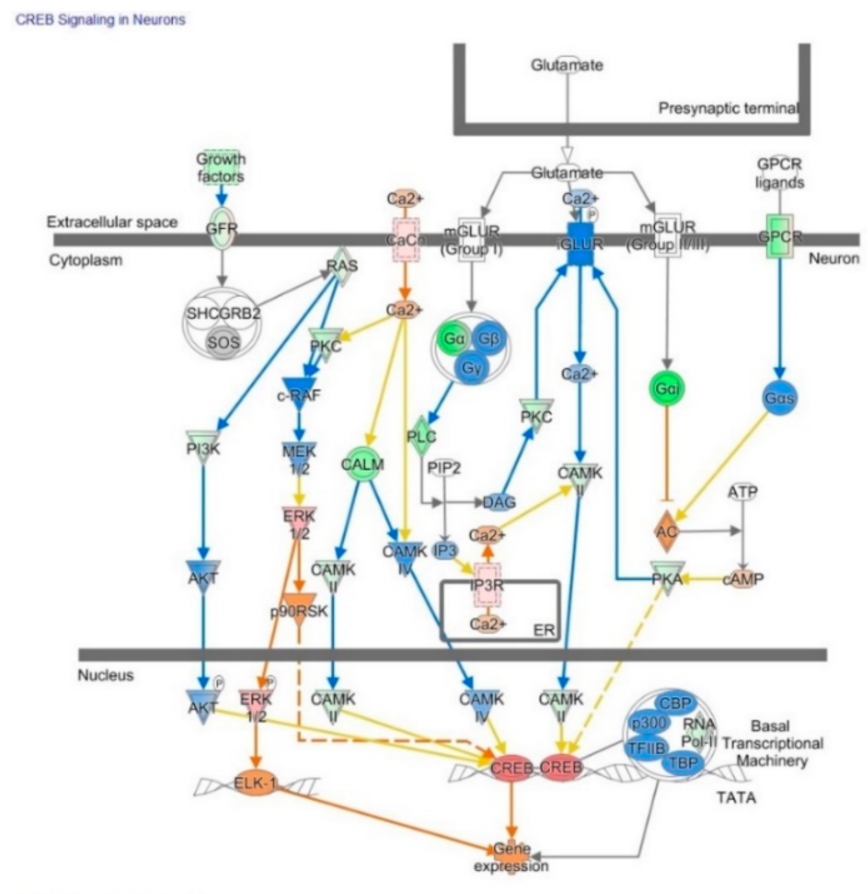

(b)

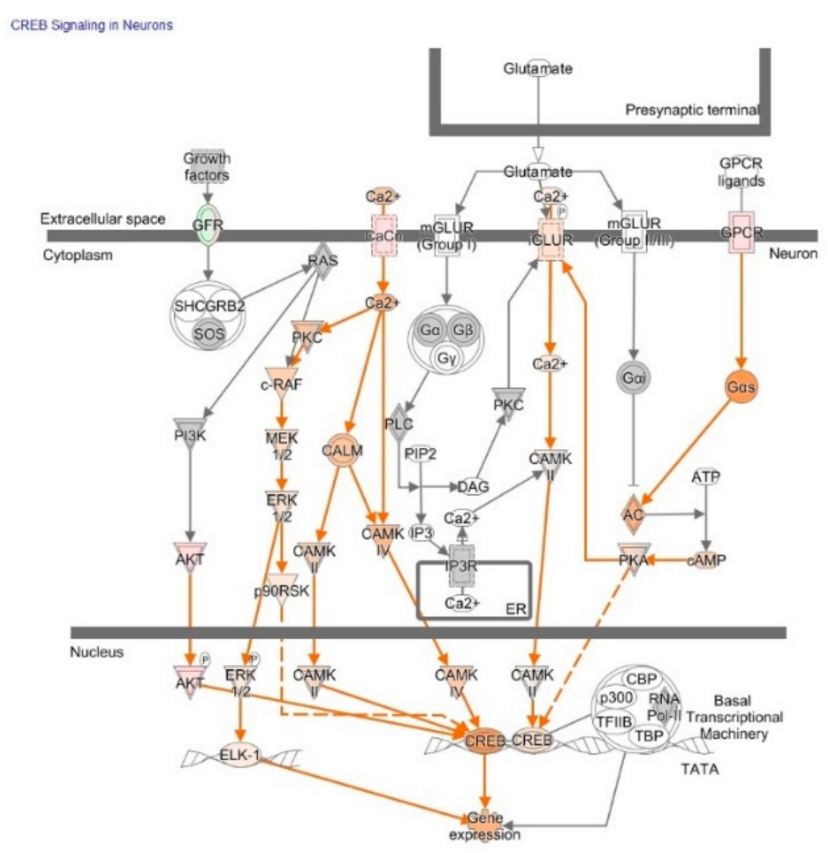

(c)

Figure 7. Effect of Rg5 on CREB signaling pathway: (a) Heatmap of gene expressions (in fold changes compared to control, red, upregulation and green, downregulation), after exposure with ginsenoside $\operatorname{Rg} 5$ at different concentrations; the $100 \mu \mathrm{M}$ signature is shown in the leftmost column as solid red or green squares indicating genes that are upregulated or downregulated, respectively; color intensity indicates the actual log-fold changes; (b) Rg5 at a concentration of $100 \mu \mathrm{M}-$ predicted inhibition (blue) and activation (brown); (c) $\operatorname{Rg} 5$ at a concentration of $1 \mu \mathrm{M}$-predicted inhibition (blue) and activation (brown). 


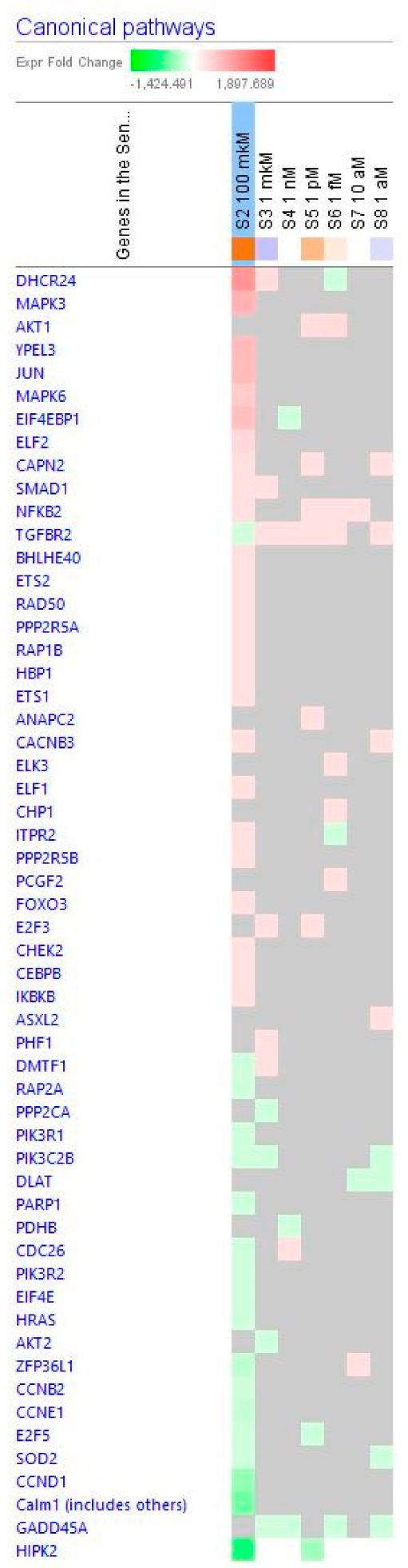

(a)

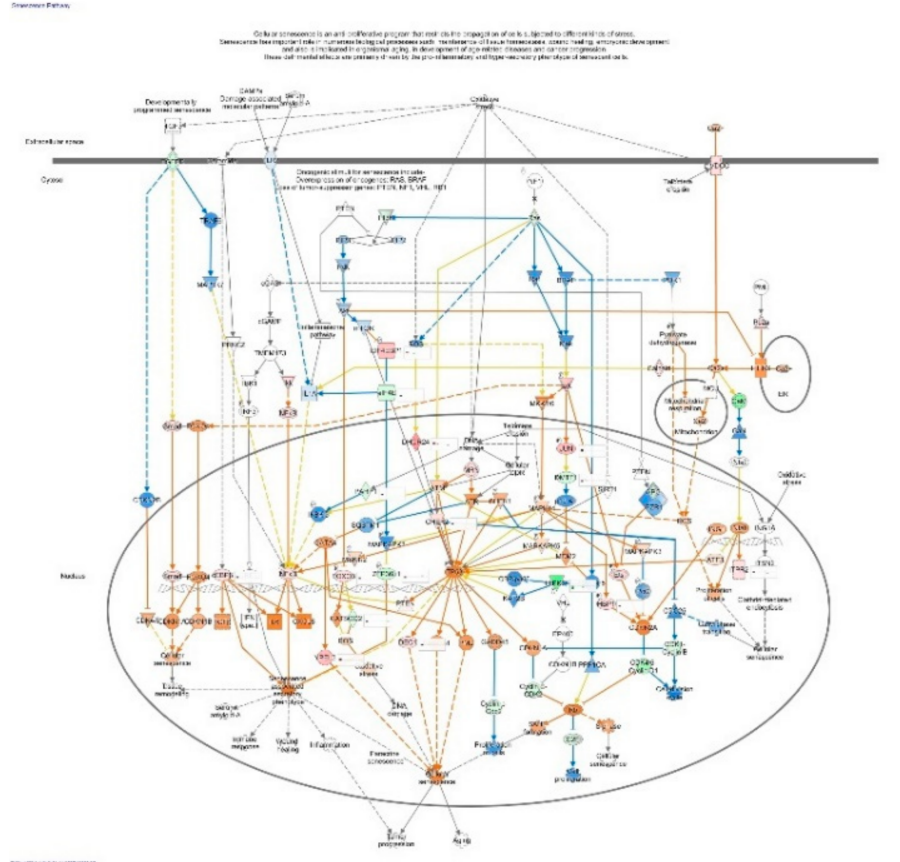

(b)

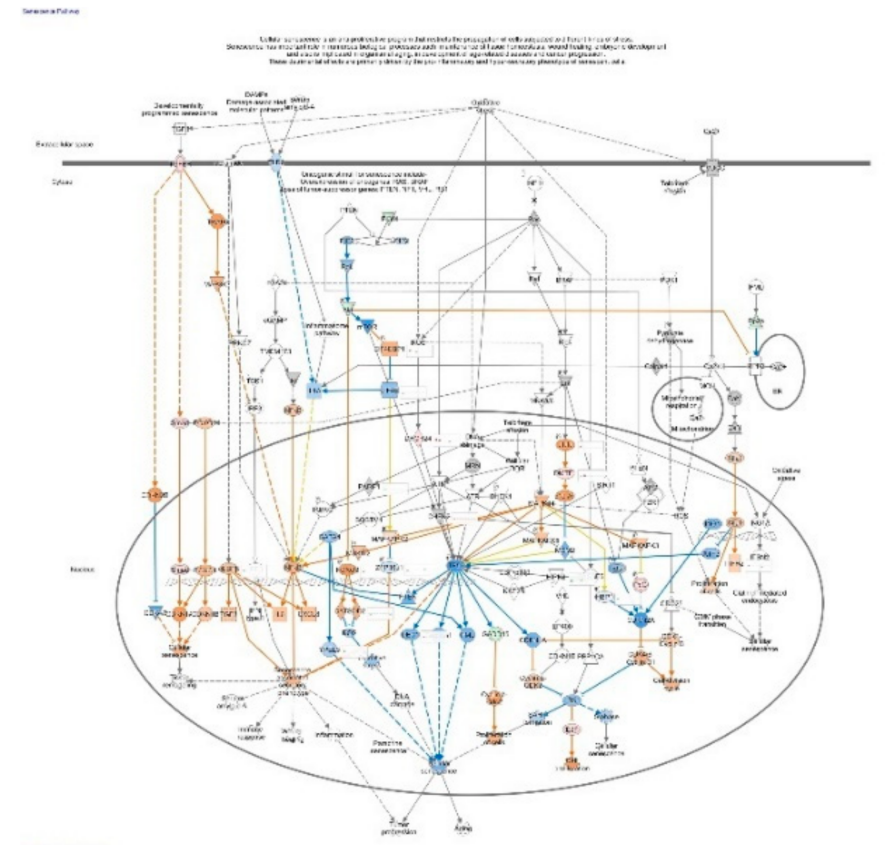

Figure 8. Effect of $\operatorname{Rg} 5$ on senescence signaling pathway: (a) Heatmap of gene expression (in fold changes compared to control, red, upregulation and green, downregulation), after exposure with ginsenoside $\operatorname{Rg} 5$ at different concentrations; the $100 \mu \mathrm{M}$ signature is shown in the leftmost column as solid red or green squares indicating genes that are upregulated or downregulated, respectively; color intensity indicates the actual log-fold changes; (b) Rg5 at a concentration of $100 \mu \mathrm{M}-$ predicted inhibition (blue) and activation (brown); (c) $\operatorname{Rg} 5$ at a concentration of $1 \mu \mathrm{M}$-predicted inhibition (blue) and activation (brown). 
Table 3 shows some primary endpoints of the estrogen receptors signaling pathway and the number of genes matching the pathway for predicting positive $(+)$ or negative $(-)$ effects of $\operatorname{Rg} 5$ in cellular functions associated with senescence signaling. Importantly, Rg5 at concentrations of $10^{-6}-10^{-18} \mathrm{M}$ activated the cell division cycle and inhibited cellular senescence, while at the concentration of $10^{-4} \mathrm{M}$ reverse effects are noticed.

Table 3. The number of genes matching senescence signaling pathway and predicted effects of Rg5 in cellular processes associated with neurotransmission ${ }^{1}$.

\begin{tabular}{ccccccccc}
\hline Concentration of Rg5, $\mathbf{M}$ & & $\mathbf{1 0}^{-\mathbf{4}}$ & $\mathbf{1 0}^{-\mathbf{6}}$ & $\mathbf{1 0}^{-\mathbf{9}}$ & $\mathbf{1 0}^{-\mathbf{1 2}}$ & $\mathbf{1 0}^{-\mathbf{1 5}}$ & $\mathbf{1 0}^{-\mathbf{1 7}}$ & $\mathbf{1 0}^{-\mathbf{1 8}}$ \\
\hline No. of matching genes & & 43 & 10 & 5 & 8 & 9 & 3 \\
\hline Cell division cycle & function & - & + & + & + & + & + \\
Cellular senescence & function & + & - & - & - & - & - \\
\hline
\end{tabular}

${ }^{1} 0$-no effect; (+)—activation, (-) - inhibition compared to control.

\section{Eukaryotic Translation Initiation Factor EIF2 Signaling}

The effect of ginsenoside $\operatorname{Rg} 5$ at all tested concentrations ( $1 \mathrm{aM}, 10 \mathrm{aM}, 1 \mathrm{fM}, 1 \mathrm{pM}$, $1 \mathrm{nM}, 1 \mu \mathrm{M}$ and $100 \mu \mathrm{M}$ ) on gene expression involved in the EIF2 signaling pathway is shown in Figure 9a. Figure 9b,c present predicted activation and inhibition of the pathway at concentrations of $100 \mu \mathrm{M}$ and $1 \mu \mathrm{M} \operatorname{Rg} 5$, respectively. The effects of $\operatorname{Rg} 5$ at all other tested concentrations are included in Supplement 6 in detail. Table 4 shows some primary endpoints of the EIF2 signaling pathway and the number of genes matching the pathway for predicting positive (+) or negative (-) effects of $\operatorname{Rg} 5$ in various diseases and cellular functions associated with the EIF2 signaling.

Notably, Rg5 positively regulates glucose uptake and negatively endoplasmic reticulum stress response at all low concentrations from $10^{-9} \mathrm{M}$, and the reversal effect at the concentration of $10^{-4} \mathrm{M}$.

2.2.3. Nuclear Receptors Signaling and Transcriptional Regulators Signaling Estrogen Receptors Signaling

The effect of ginsenoside Rg5 at all tested concentrations ( $1 \mathrm{aM}, 10 \mathrm{aM}, 1 \mathrm{fM}, 1 \mathrm{pM}$, $1 \mathrm{nM}, 1 \mu \mathrm{M}$ and $100 \mu \mathrm{M})$ on gene expression involved in estrogen receptors signaling pathway is shown in Figure 10a. Figure 10b,c present predicted activation and inhibition of the pathway at concentrations of $100 \mu \mathrm{M}$ and $1 \mu \mathrm{M}$ Rg5, respectively. The effects of Rg5 at all other tested concentrations are included in Supplement 7 in detail.

Table 4. The number of genes matching EIF2 signaling pathway and predicted effects of Rg5 in various diseases and cellular functions associated with intracellular signaling ${ }^{1}$.

\begin{tabular}{ccccccccc}
\hline Concentration of Rg5, $\mathbf{M}$ & & $\mathbf{1 0}^{-\mathbf{4}}$ & $\mathbf{1 0}^{-\mathbf{6}}$ & $\mathbf{1 0}^{-\mathbf{9}}$ & $\mathbf{1 0}^{-\mathbf{1 2}}$ & $\mathbf{1 0}^{-\mathbf{1 5}}$ & $\mathbf{1 0}^{-\mathbf{1 7}}$ & $\mathbf{1 0}^{-\mathbf{1 8}}$ \\
\hline No. of matching genes & & 32 & 3 & 8 & 5 & 9 & 8 \\
\hline Cardio-protection & disease & + & 0 & - & - & - & - \\
ER stress response & function & + & 0 & - & - & - & - \\
Uptake of D-glucose & function & - & 0 & + & + & + & + \\
Vascularization & function & - & 0 & - & - & 0 & 0 \\
Assembly of stress granule & function & - & 0 & - & - & 0 & 0 \\
Translation/protein elongation & function & - & - & - & - & + & - \\
\hline
\end{tabular}

\footnotetext{
${ }^{1} 0$-no effect; (+) - activation, (-) -inhibition compared to control.
} 


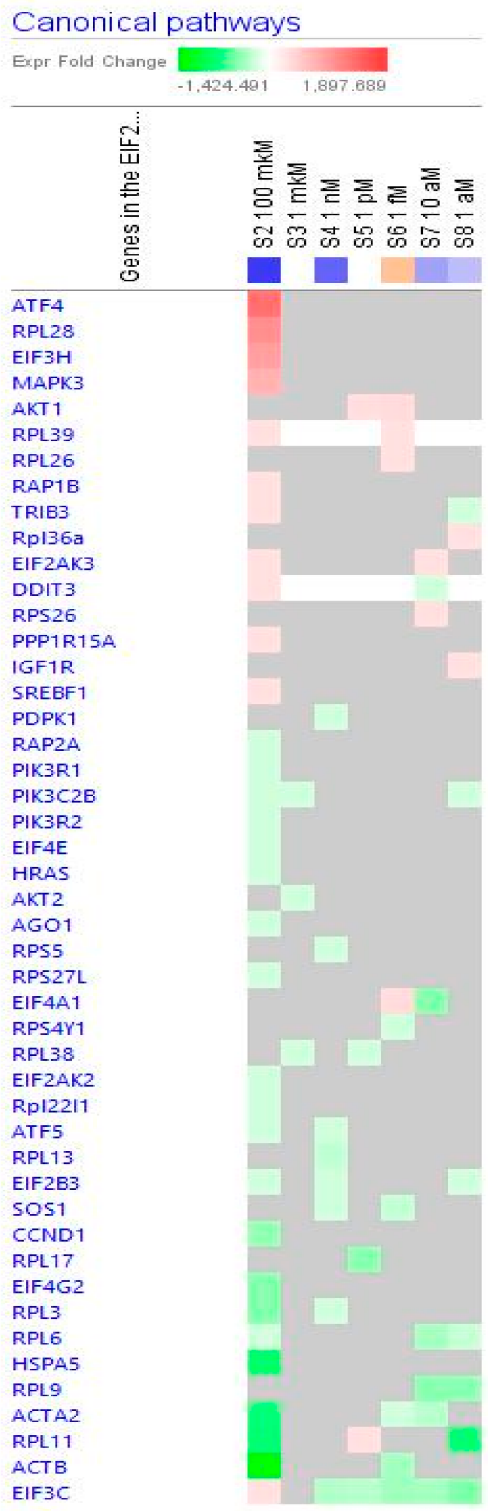

(a)

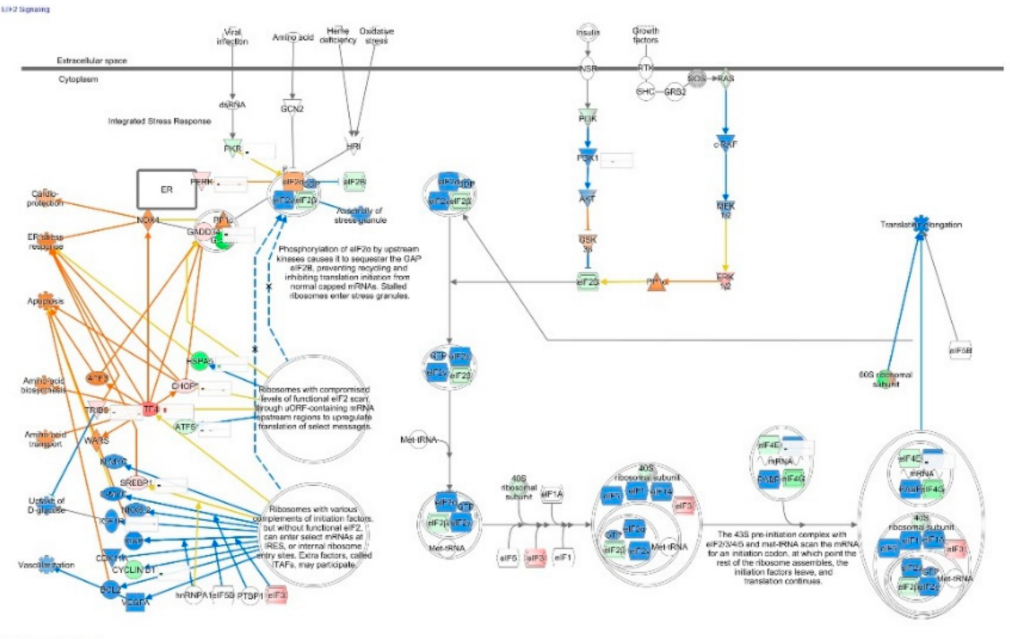

(b)

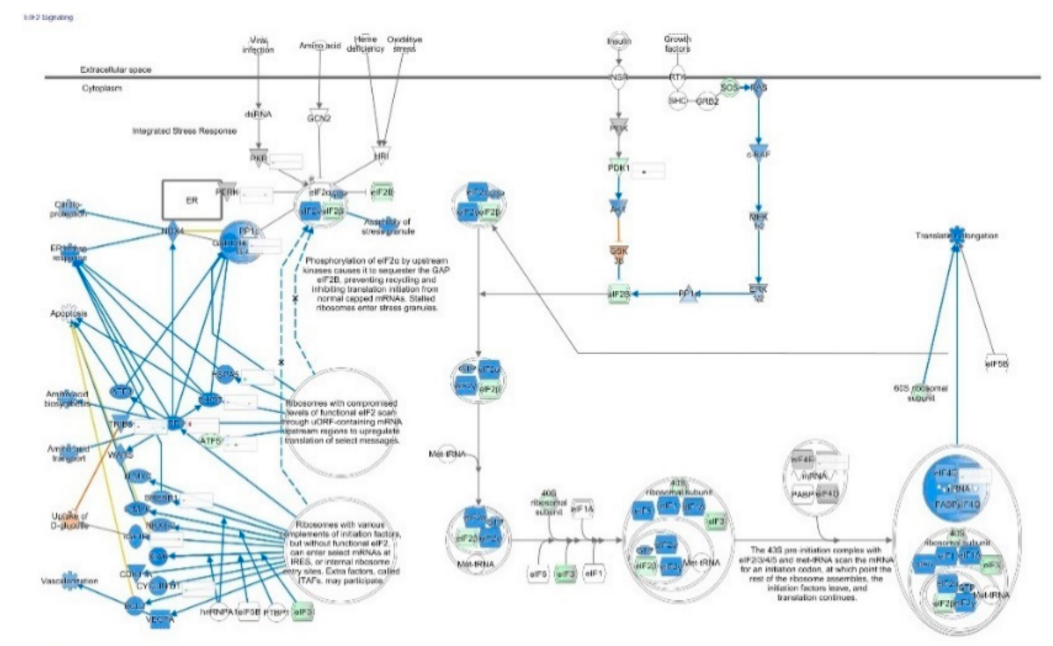

(c)

Figure 9. Effect of Rg5 on EIF2 signaling pathway: (a) Heatmap of gene expression (in fold changes compared to control, red, upregulation and green, downregulation), after exposure with ginsenoside $\operatorname{Rg} 5$ in different concentrations; the $100 \mu \mathrm{M}$ signature is shown in the leftmost column as solid red or green squares indicating genes that are upregulated or downregulated, respectively; color intensity indicates the actual log-fold changes; (b) Rg5 at a concentration of $100 \mu \mathrm{M}-$ predicted inhibition (blue) and activation (brown); (c) $\operatorname{Rg} 5$ at a concentration of $1 \mu \mathrm{M}$-predicted inhibition (blue) and activation (brown). 


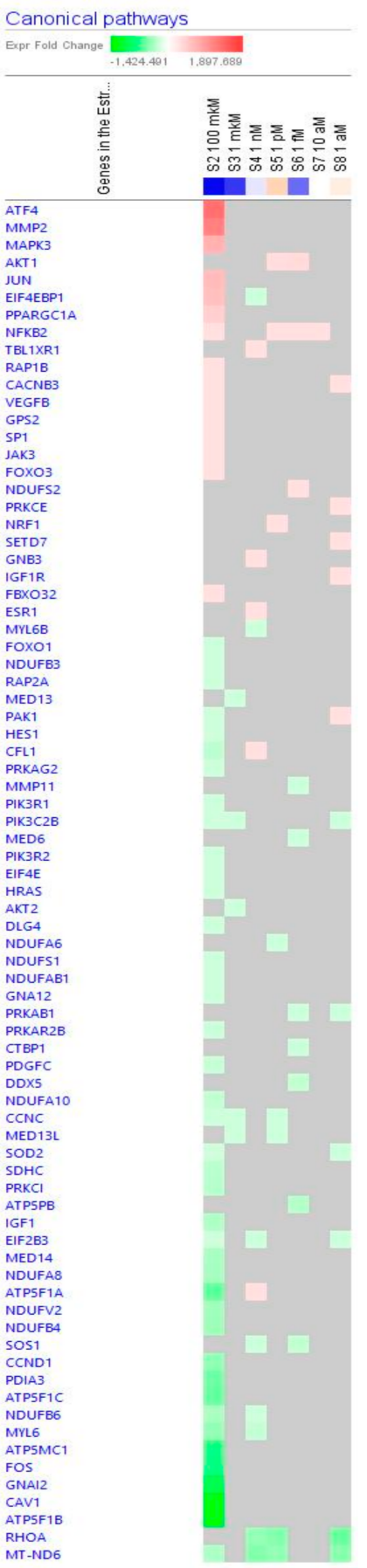

(a)

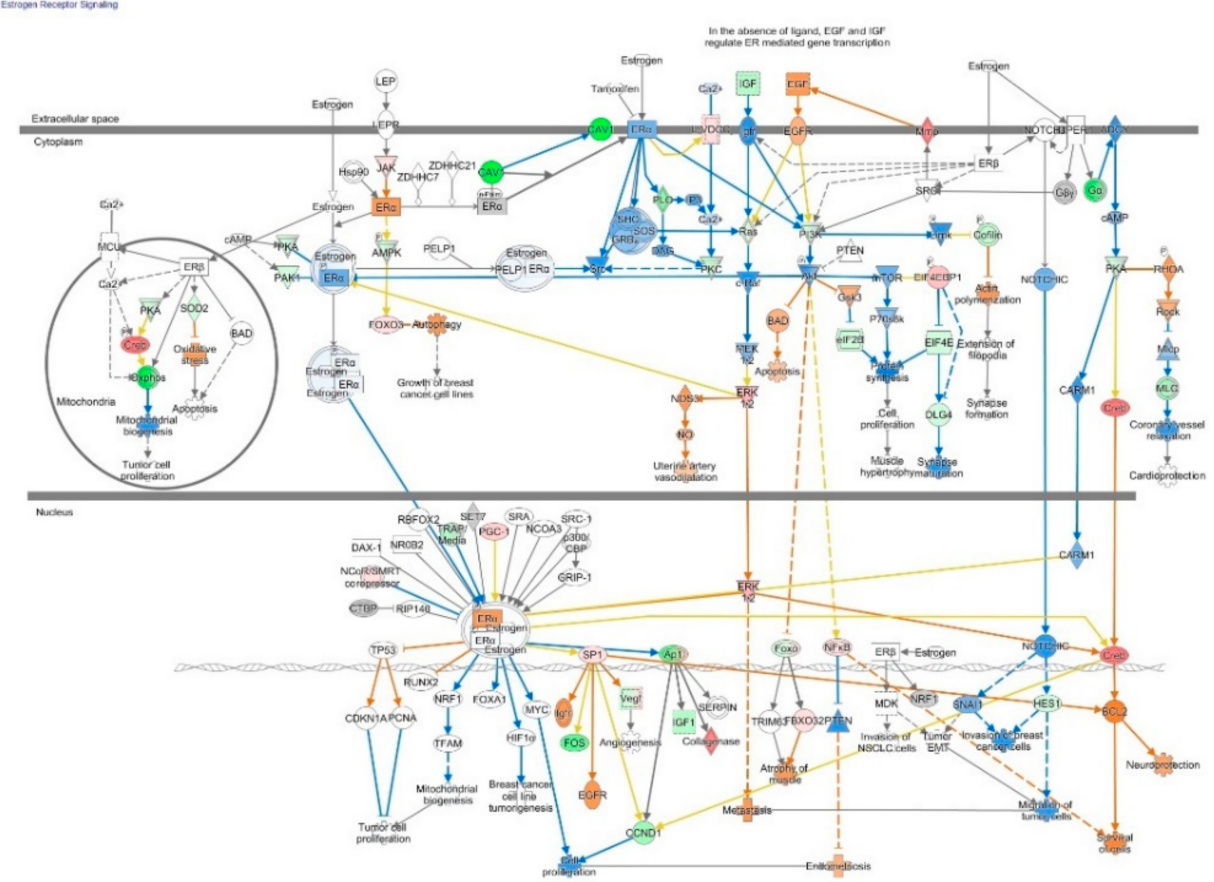

(b)

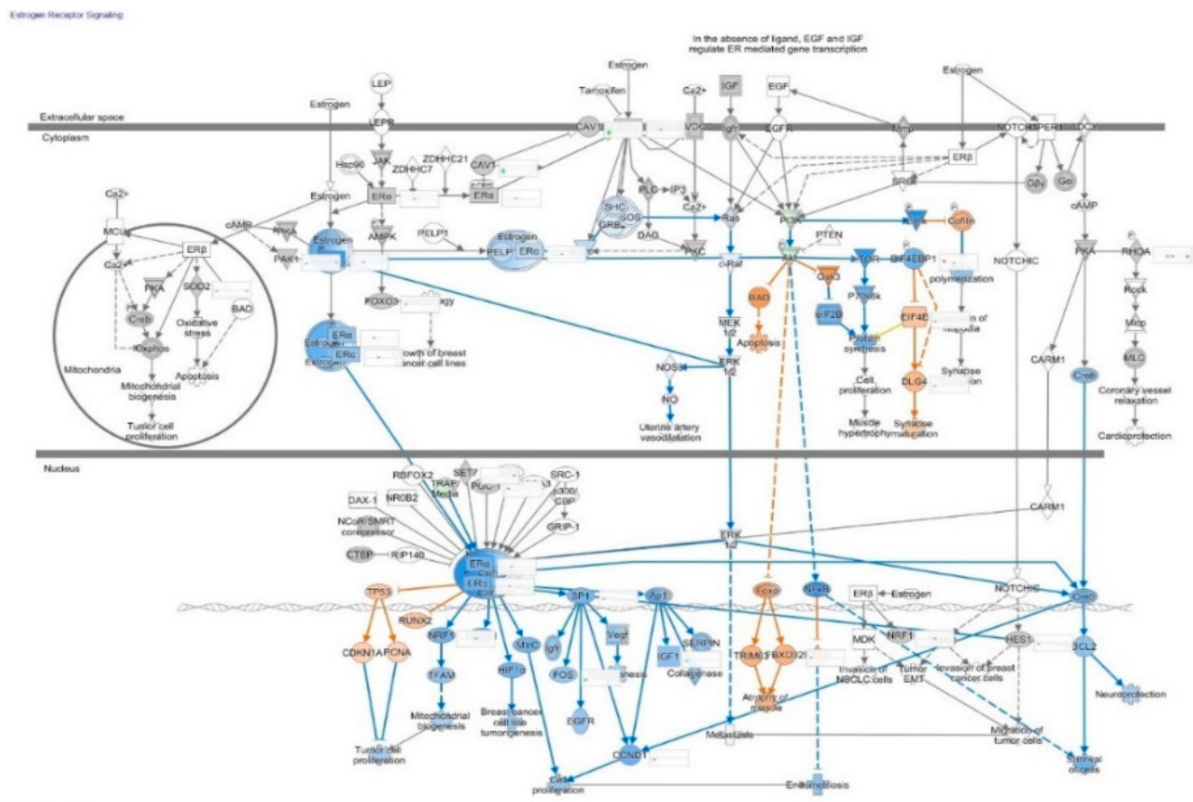

(c)

Figure 10. Effect of Rg5 on estrogen receptors signaling pathway: (a) Heatmap of gene expression (in fold changes compared to control, red, upregulation and green, downregulation), after exposure with ginsenoside Rg5 at different concentrations; the $100 \mu \mathrm{M}$ signature is shown in the leftmost column as solid red or green squares indicating genes that are upregulated downregulated, respectively; color intensity indicates the actual log-fold changes; (b) $\operatorname{Rg} 5$ in the concentration of $100 \mu \mathrm{M}-$ predicted inhibition (blue) and activation (brown); (c) $\operatorname{Rg} 5$ in the concentration of $1 \mu \mathrm{M}$-predicted inhibition (blue) and activation (brown).

Table 5 outlines some primary endpoints of the estrogen receptors signaling pathway and the number of genes matching the pathway for predicting positive $(+)$ or negative 
(-) effects of $\operatorname{Rg} 5$ in various diseases and cellular functions associated with estrogen receptors signaling.

Table 5. The number of genes matching estrogen receptors signaling pathway and predicted effects of Rg5 in various diseases and cellular functions associated with neurotransmission ${ }^{1}$.

\begin{tabular}{|c|c|c|c|c|c|c|c|c|}
\hline Concentration of $\operatorname{Rg} 5, \mathrm{M}$ & & $10^{-4}$ & $10^{-6}$ & $10^{-9}$ & $10^{-12}$ & $10^{-15}$ & $10^{-17}$ & $10^{-18}$ \\
\hline No. of matching genes & & 56 & 5 & 13 & 8 & 10 & 1 & 11 \\
\hline Atrophy of muscle & disease & + & + & - & - & - & 0 & + \\
\hline Breast cancer cell line tumorigenesis & disease & 0 & - & + & 0 & - & 0 & + \\
\hline Metastasis & disease & + & 0 & - & 0 & - & 0 & 0 \\
\hline Oxidative stress & disease & + & 0 & 0 & 0 & 0 & 0 & + \\
\hline Tumor cell proliferation & disease & 0 & - & + & 0 & - & 0 & +0 \\
\hline Angiogenesis & function & 0 & - & + & + & - & 0 & + \\
\hline Apoptosis & function & + & + & - & - & - & 0 & + \\
\hline Cell proliferation & function & - & - & + & 0 & - & 0 & + \\
\hline Coronary vessel relaxation & function & - & 0 & - & + & 0 & 0 & + \\
\hline Neuroprotection & function & + & - & + & + & + & + & + \\
\hline Survival of cells & function & + & - & + & + & + & + & 0 \\
\hline Synapse maturation & function & - & + & + & - & - & 0 & + \\
\hline
\end{tabular}

${ }^{1} 0$-no effect; (+)—activation, (-)—inhibition compared to control.

Notably, Rg5 is expected to increase neuroprotection and survival of cells in a wide range of concentrations from $10^{-9}$ to $10^{-18} \mathrm{M}$, but inhibits muscle atrophy and apoptosis at the concentrations from $10^{-9}$ to $10^{-15} \mathrm{M}$.

Sirtuin Signaling Pathway

The effect of ginsenoside Rg5 at all tested concentrations ( $1 \mathrm{aM}, 10 \mathrm{aM}, 1 \mathrm{fM}, 1 \mathrm{pM}$, $1 \mathrm{nM}, 1 \mu \mathrm{M}$ and $100 \mu \mathrm{M}$ ) on gene expression involved in SIRT signaling pathway is shown in Figure 11a. Figure 11b,c present the predicted activation and inhibition of the pathway at concentrations of $100 \mu \mathrm{M}$ and $1 \mu \mathrm{M}$ Rg5, respectively. The effects of Rg5 on SIRT signaling pathway gene expression at all other tested concentrations are included in Supplement 8 in detail.

\subsubsection{Apoptosis and Cancer Signaling}

Death Receptor Signaling

The effect of ginsenoside Rg5 at all tested concentrations ( $1 \mathrm{aM}, 10 \mathrm{aM}, 1 \mathrm{fM}, 1 \mathrm{pM}$, $1 \mathrm{nM}, 1 \mu \mathrm{M}$ and $100 \mu \mathrm{M}$ ) on gene expression involved in the death receptors signaling pathway is shown in Figure 12a. 


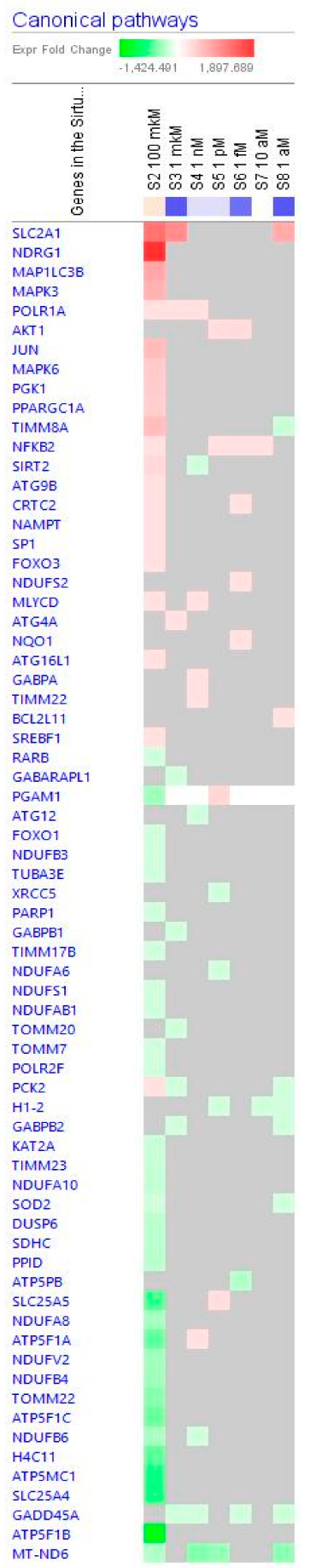

(a)

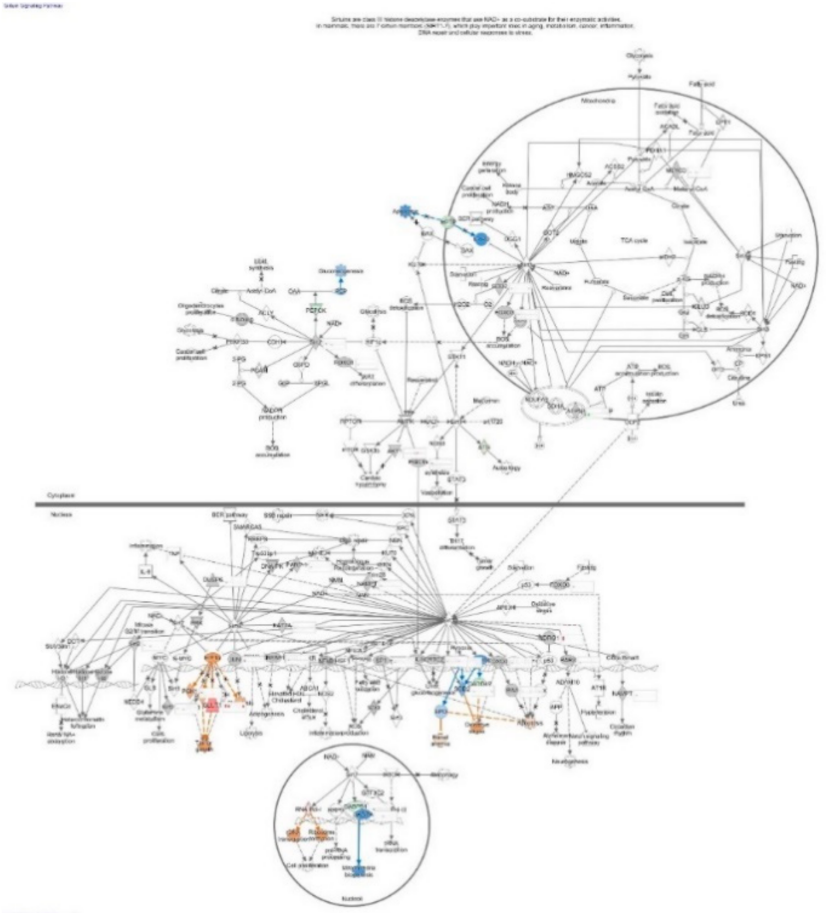

(b)

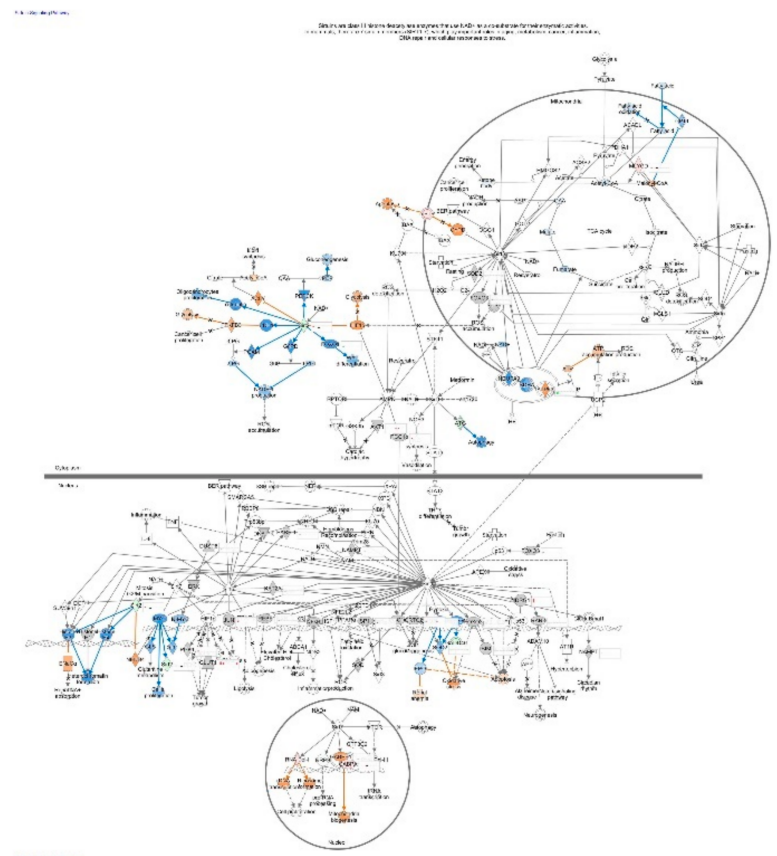

(c)

Figure 11. Effect of Rg5 on SIRT signaling pathway in neurons: (a)-Heatmap of gene expressions (in fold changes compared to control, red, upregulation and green-downregulation), after exposure of neurons with ginsenoside Rg5 in different concentrations; the $100 \mu \mathrm{M}$ signature is shown in the leftmost column as solid red or green squares indicating genes that are upregulated or down-regulated, respectively; color intensity indicates the actual log-fold changes; (b) $\operatorname{Rg} 5$ in the concentration of $100 \mu \mathrm{M}$ - predicted inhibition (blue) and activation (brown); (c) $\operatorname{Rg} 5$ in the concentration of $1 \mathrm{nM}$ - predicted inhibition (blue) and activation (brown). 


\begin{tabular}{l} 
Canonical pathways \\
Expr Fold Change \\
\hline
\end{tabular}

(a)

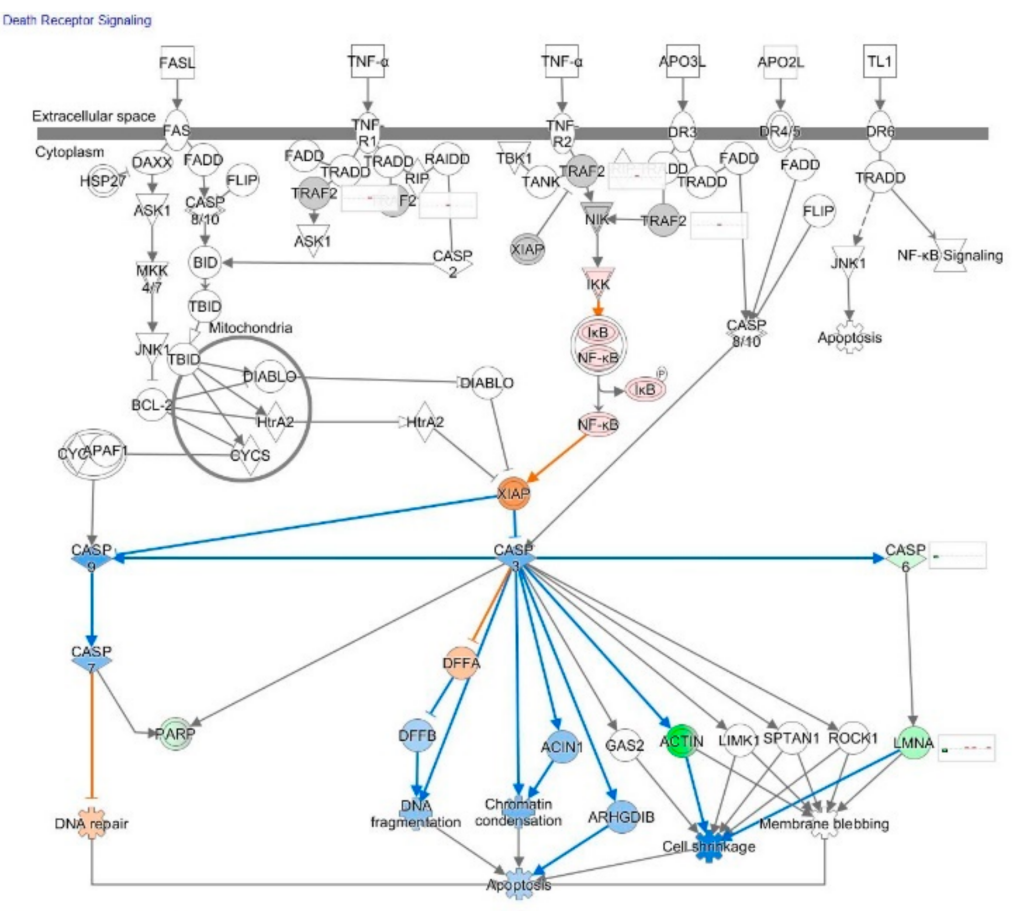

(b)

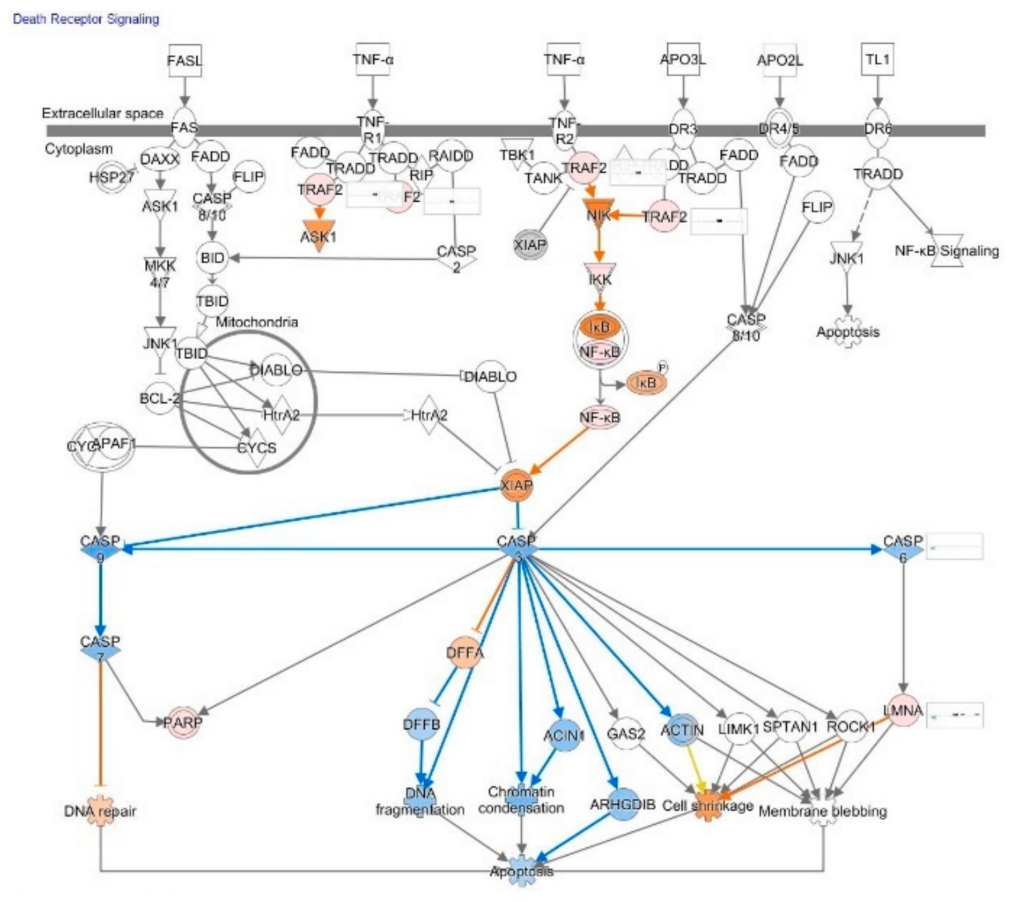

(c)

Figure 12. Effect of $\operatorname{Rg} 5$ on death receptors signaling pathway: (a) Heatmap of gene expression (in fold changes compared to control, red, upregulation and green, downregulation), after exposure with ginsenoside Rg5 at different concentrations; the $100 \mu \mathrm{M}$ signature is shown in the leftmost column as solid red or green squares indicating genes that are upregulated or downregulated, respectively; color intensity indicates the actual log-fold changes; (b) Rg5 at a concentration of $100 \mu \mathrm{M}-$ predicted inhibition (blue) and activation (brown); (c) $\operatorname{Rg} 5$ at a concentration of $1 \mu \mathrm{M}-$ predicted inhibition (blue) and activation (brown). 
Figure $12 \mathrm{~b}, \mathrm{c}$ present predicted activation and inhibition of the pathway at a concentration of $100 \mu \mathrm{M}$ and $1 \mu \mathrm{M} \operatorname{Rg} 5$, respectively. The effects of $\operatorname{Rg} 5$ at all other tested concentrations are included in Supplement 9 in detail. Table 6 demonstrates some primary endpoints of the death receptors signaling pathway and the number of genes matching the pathway for predicting positive (+) or negative (-) effects of $\operatorname{Rg} 5$ in cellular functions associated with apoptosis.

Table 6. The number of genes matching senescence signaling pathway and predicted effects of Rg5 in cellular processes associated with apoptosis ${ }^{1}$.

\begin{tabular}{clccccccc}
\hline Concentration of Rg5, $\mathbf{M}$ & & $\mathbf{1 0}^{-\mathbf{4}}$ & $\mathbf{1 0}^{-\mathbf{6}}$ & $\mathbf{1 0}^{-\mathbf{9}}$ & $\mathbf{1 0}^{-\mathbf{1 2}}$ & $\mathbf{1 0}^{-\mathbf{1 5}}$ & $\mathbf{1 0}^{-\mathbf{1 7}}$ & $\mathbf{1 0}^{-\mathbf{1 8}}$ \\
\hline No. of matching genes & & 8 & 0 & 0 & 5 & 5 & 2 \\
\hline Apoptosis & function & - & 0 & 0 & - & - & - \\
Cell shrinkage & function & - & 0 & 0 & - & - & - \\
Chromatin condensation & function & - & 0 & 0 & - & - & - \\
DNA fragmentation & function & - & 0 & 0 & - & - & - \\
DNA repair & function & + & 0 & 0 & + & + & + \\
\hline
\end{tabular}

${ }^{1} 0$-no effect; (+)—activation, (-)—inhibition compared to control.

Remarkably, Rg5 inhibits apoptosis, cell shrinkage, chromatin condensation, DNA fragmentation and activates DNA repair at all concentrations from $10^{-4} \mathrm{M}$ to $10^{-18} \mathrm{M}$.

Tumor Microenvironment Pathway

The effect of ginsenoside Rg5 at all tested concentrations ( $1 \mathrm{aM}, 10 \mathrm{aM}, 1 \mathrm{fM}, 1 \mathrm{pM}$, $1 \mathrm{nM}, 1 \mu \mathrm{M}$ and $100 \mu \mathrm{M}$ ) on gene expression involved in tumor microenvironment signaling pathway is shown in Figure 13a. Figure 13b presents the predicted inhibition of the pathway at a concentration $1 \mu \mathrm{M} \operatorname{Rg} 5$. The effects of $\operatorname{Rg} 5$ at all other tested concentrations are included in Supplement 10 in detail.

Table 7 demonstrates some primary endpoints of the tumor microenvironment signaling pathway and the number of genes matching the pathway for predicting positive $(+)$ or negative (-) effects of $\operatorname{Rg} 5$ in various diseases and cellular functions associated with the tumor microenvironment signaling.

Table 7. The number of genes matching tumor microenvironment signaling pathway and predicted effects of Rg5 in various diseases and cellular processes associated with neurotransmission ${ }^{1}$.

\begin{tabular}{ccccccccc}
\hline Concentration of Rg5, $\mathbf{M}$ & & $\mathbf{1 0}^{-\mathbf{4}}$ & $\mathbf{1 0}^{-\mathbf{6}}$ & $\mathbf{1 0}^{-\mathbf{9}}$ & $\mathbf{1 0}^{-\mathbf{1 2}}$ & $\mathbf{1 0}^{-\mathbf{1 5}}$ & $\mathbf{1 0}^{-\mathbf{1 7}}$ & $\mathbf{1 0}^{-\mathbf{1 8}}$ \\
\hline No. of matching genes & & 29 & 5 & 2 & 4 & 7 & 4 & 5 \\
\hline Apoptosis of tumor cells & Disease & -+ & ++ & 0 & - & - & -+ & -+ \\
Viability of tumor cells & function & + & - & 0 & + & + & + \\
Survival of tumor cells & disease & + & - & 0 & + & + & + & + \\
Proliferation of tumor cells & disease & - & - & 0 & + & + & + \\
Metastasis & disease & + & - & 0 & + & + & + \\
Tumor cell invasion & disease & - & - & 0 & + & + & + \\
\hline
\end{tabular}

${ }^{1} 0$-no effect; (+)—activation, (-)—inhibition compared to control.

Importantly, Rg5 may activate apoptosis of tumor cells, increase viability and survival of tumor cells and metastasis, whereas proliferation of tumor cells and tumor cell invasion are potentially reduced at the concentration of $10^{-4} \mathrm{M}$.

The Programmed Cell Death Receptor PD-1 Cancer Immunotherapy Pathway

The effect of ginsenoside Rg5 at all tested concentrations ( $1 \mathrm{aM}, 10 \mathrm{aM}, 1 \mathrm{fM}, 1 \mathrm{pM}$, $1 \mathrm{nM}, 1 \mu \mathrm{M}$ and $100 \mu \mathrm{M}$ ) on gene expression involved in the programmed cell death receptor PD-1 cancer immunotherapy signaling pathway is shown in Figure 14a. 


\section{Canonical pathways}

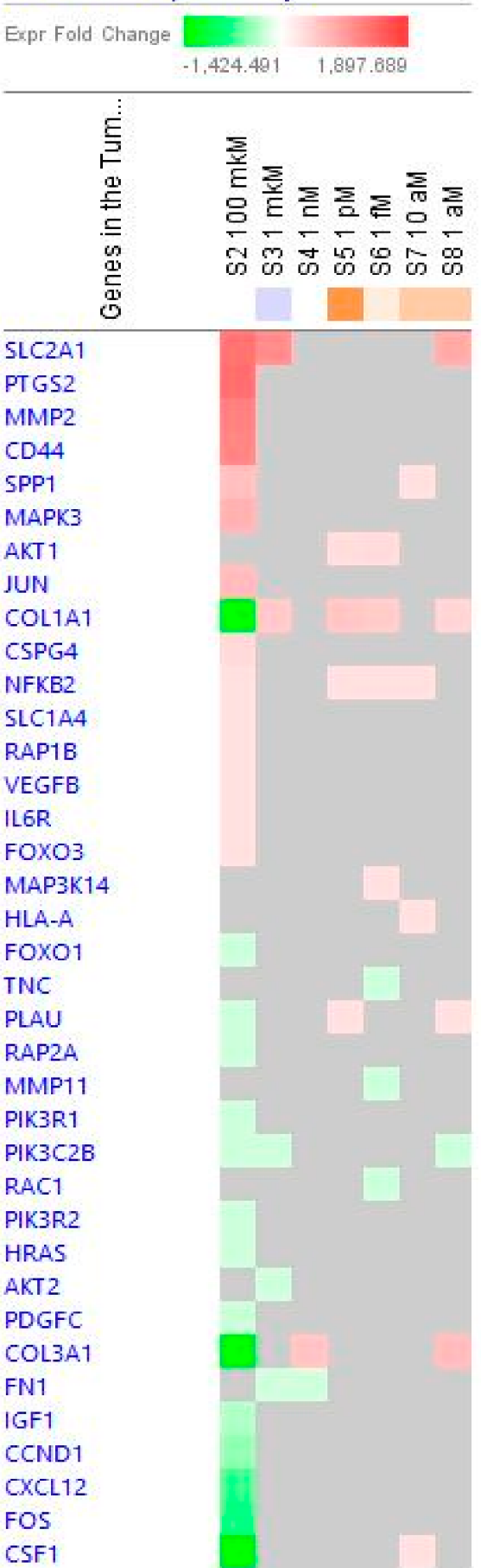

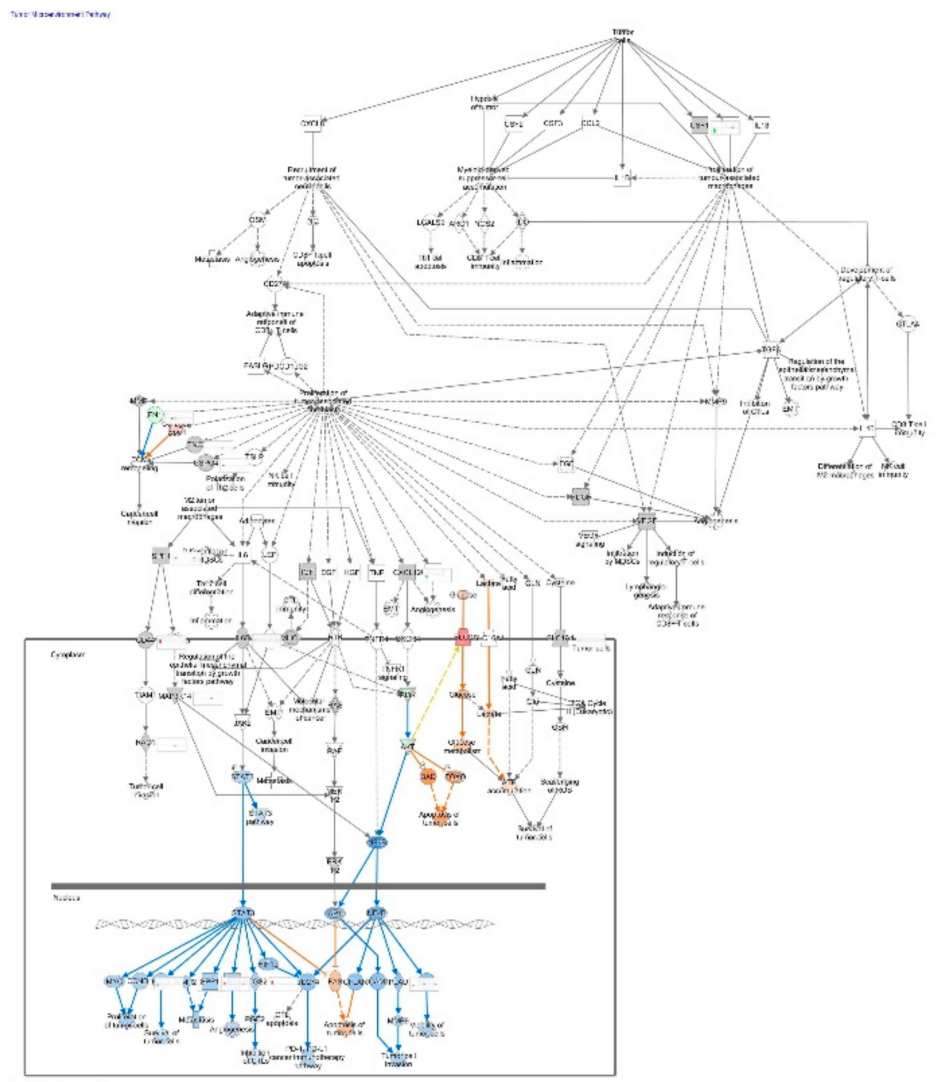

(a)

(b)

Figure 13. Effect of Rg5 on tumor microenvironment signaling pathway: (a) Heatmap of gene expression (in fold changes compared to control, red, upregulation and green, downregulation), after exposure with ginsenoside Rg5 in different concentrations; the $100 \mathrm{mM}$ signature is shown in the leftmost column as solid red or green squares indicating genes that are upregulated or downregulated, respectively; color intensity indicates the actual log-fold changes; (b) $\operatorname{Rg} 5$ at a concentration of $1 \mu \mathrm{M}$-predicted inhibition (blue) and activation (brown). 


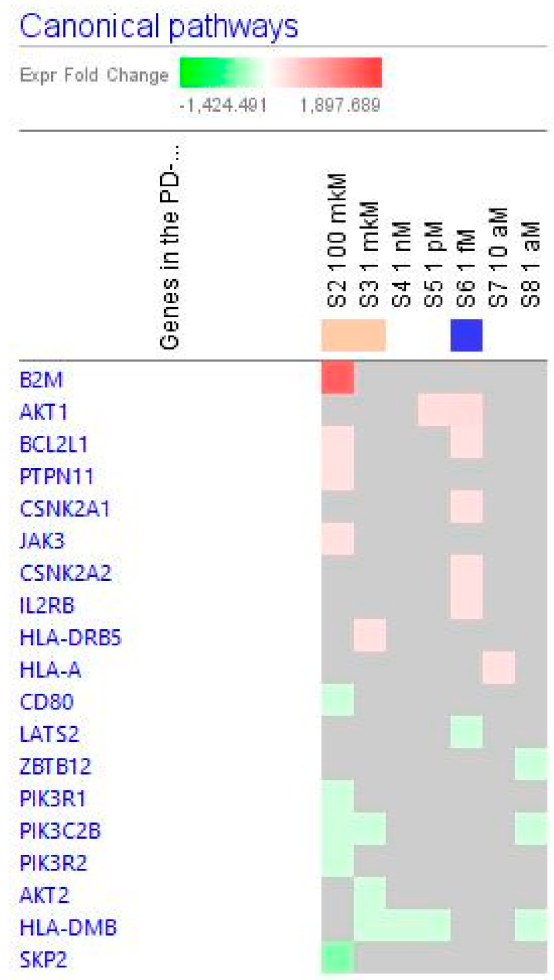

(a)

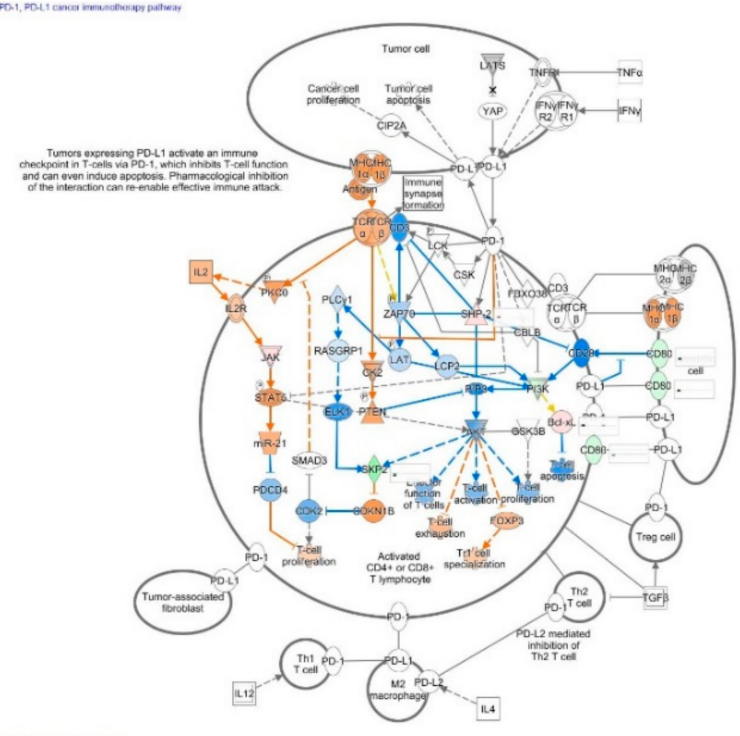

(c)

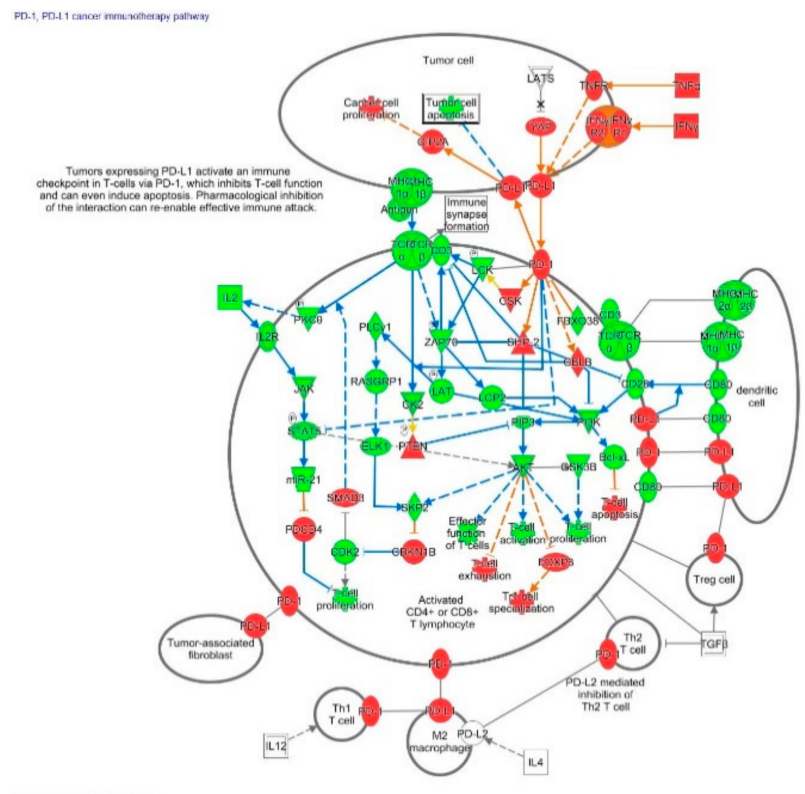

(b)

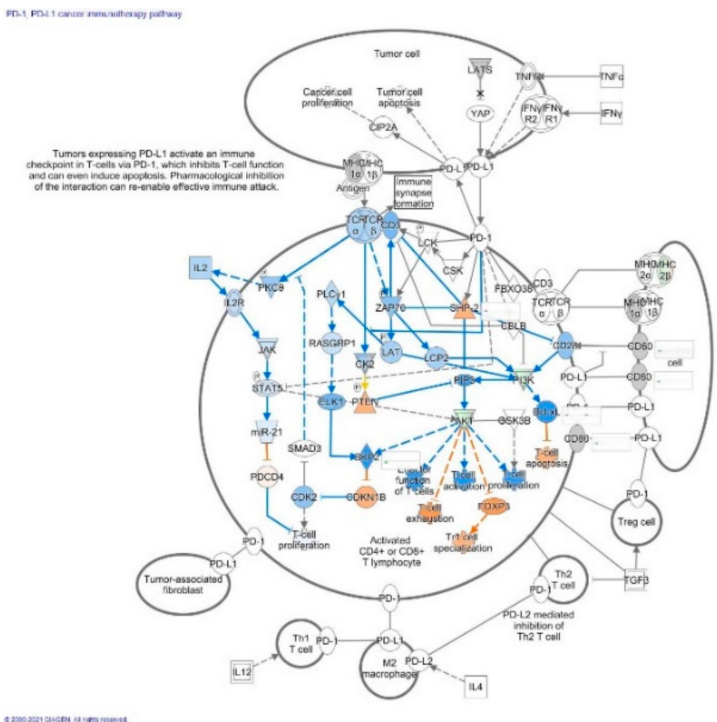

(d)

Figure 14. Effect of Rg5 on PD-1 cancer immunotherapy signaling pathway: (a) Heatmap of gene expression (in fold changes compared to control, red, upregulation and green, downregulation), after exposure with ginsenoside Rg5 at different concentrations; the $100 \mu \mathrm{M}$ signature is shown in the leftmost column as solid red or green squares indicating genes that are upregulated or downregulated, respectively; color intensity indicates the actual log-fold changes; (b) canonical pathway activation state; (c) $\operatorname{Rg} 5$ at a concentration of $100 \mu \mathrm{M}$-predicted inhibition (blue) and activation (brown); (d) Rg5 at a concentration of $1 \mu \mathrm{M}$-predicted inhibition (blue) and activation (brown). 
Figure $14 \mathrm{~b}$ illustrates the predicted activation of the PD- 1 cancer immunotherapy signaling pathway, while Figure 14c,d show the effects of Rg5 at concentrations $100 \mu \mathrm{M}$ and $1 \mu \mathrm{M}$, respectively. The effects of $\operatorname{Rg} 5$ at all other tested concentrations are included in Supplement 11 in detail. Table 8 outlines some primary endpoints of the apoptosis receptor PD-1 cancer immunotherapy signaling pathway and the number of genes matching the pathway for predicting positive (+) or negative (-) effects of Rg5 in various diseases and cellular functions associated with the PD-1 signaling

Table 8. The number of genes matching apoptosis receptor PD-1 cancer immunotherapy signaling pathway and predicted effects of Rg5 in various diseases and cellular processes associated with cancer immunotherapy ${ }^{1}$.

\begin{tabular}{clccccccc}
\hline Concentration Rg5, $\mathbf{M}$ & & $\mathbf{1 0}^{-\mathbf{4}}$ & $\mathbf{1 0}^{-\mathbf{6}}$ & $\mathbf{1 0}^{-\mathbf{9}}$ & $\mathbf{1 0}^{-\mathbf{1 2}}$ & $\mathbf{1 0}^{-\mathbf{1 5}}$ & $\mathbf{1 0}^{-\mathbf{1 7}}$ & $\mathbf{1 0}^{-\mathbf{1 8}}$ \\
\hline No. of matching genes & & 9 & 4 & 1 & 2 & 6 & 1 \\
\hline Cancer cell proliferation & disease & + & - & - & 0 & + & + \\
T-cell exhaustion & disease & + & + & 0 & - & - & 0 & + \\
Effector function of T cells & function & - & - & 0 & + & + & 0 \\
T-cell apoptosis & function & - & + & 0 & 0 & - & - & + \\
T-cell proliferation & function & - & - & 0 & + & + & 0 & 0 \\
T-cell activation & function & - & - & 0 & + & + & 0 \\
Tr1 cell specialization & function & + & + & 0 & - & - & 0 \\
\hline
\end{tabular}

${ }^{1} 0$-no effect; (+)—activation, (-)—inhibition compared to control.

Overall, Rg5 activates the PD- 1 signaling pathway at concentrations between $10^{-4}$ and $10^{-6} \mathrm{M}$.

\subsection{Effect of Ginsenoside Rg5 on Metabolic Pathways}

Figure 15 shows the effect of various concentrations of ginsenoside Rg5 on significantly $(-\log \mathrm{p}$-value $>1.3, \mathrm{z}$-score $>2)$ deregulated canonical metabolic pathways.

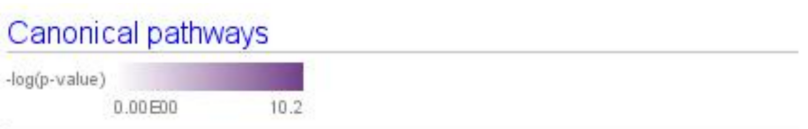

\begin{tabular}{|c|c|c|c|c|c|c|}
\hline & 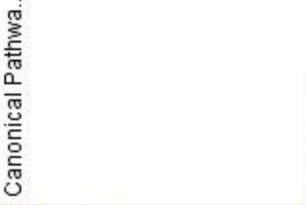 & 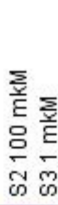 & & & & \\
\hline Superpathway of Cholesterol & I Biosynthesis & & - & - & & .. \\
\hline Cholesterol Biosynthesis I & & & - & - & & - . \\
\hline Cholesterol Biosynthesis II (vi) & ia 24,25-dihydrolanosterol) & & - & - & & - . \\
\hline Cholesterol Biosynthesis III (V) & ia Desmosterol) & & - & - & & - . \\
\hline Oxidative Phosphorylation & & • & - & - & - & - \\
\hline Zymosterol Biosynthesis & & - & - & - & - & - . \\
\hline Superpathway of Geranylger & anyldiphosphate Biosynthesi... & & - & - & - & - . \\
\hline Mevalonate Pathway I & & & - & - & - & - \\
\hline Valine Degradation I & & . & - & - & - & - . \\
\hline Glutathione Redox Reactions & & - . & & - & - & - \\
\hline Triacylglycerol Biosynthesis & & - & & & - & - . \\
\hline tRNA Charging & & -. & - & - & - & \\
\hline
\end{tabular}

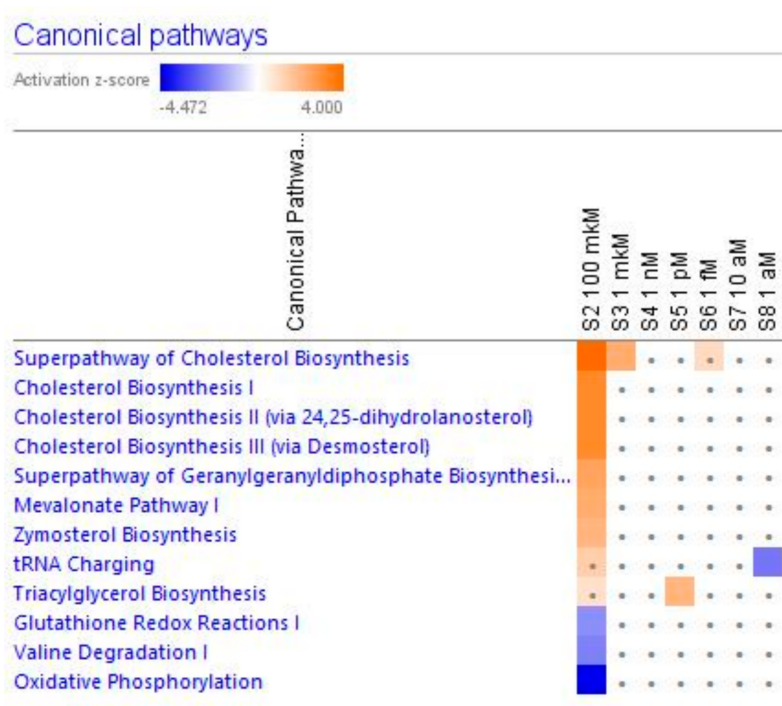

(b)

Figure 15. Effect of Rg5 at concentrations of $1 \mathrm{aM}, 10 \mathrm{aM}, 1 \mathrm{fM}, 1 \mathrm{pM}, 1 \mathrm{nM}, 1 \mu \mathrm{M}$ and $100 \mu \mathrm{M}$ ) on significantly deregulated metabolic signaling pathways. (a) The brown color shows the predicted activation, blue color-predicted inhibition of signaling pathway; the symbol shows that the activation z-score was $<2$. (b) the symbol shows that the $-\log p-$ value was $<1.3$.

Some of them were observed at all tested concentrations, including the cholesterol biosynthesis metabolic super-pathway (Figure 16). 


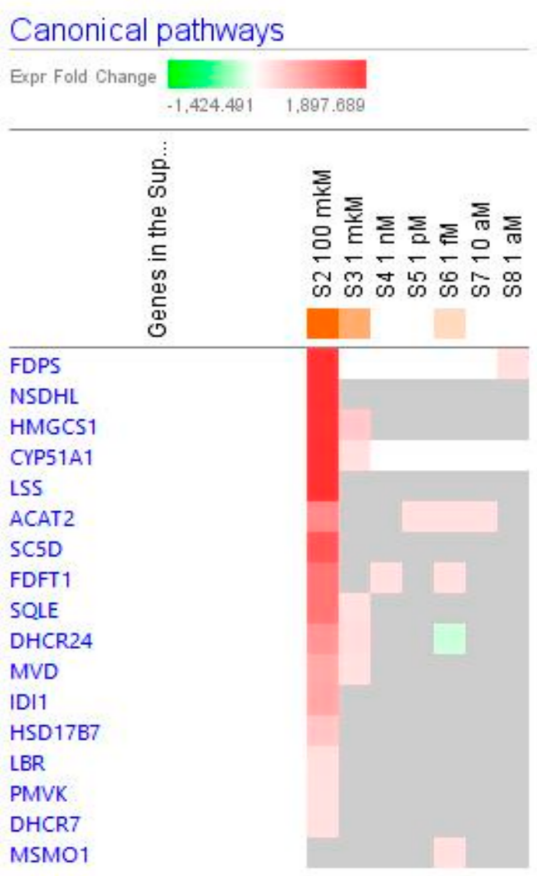

Figure 16. Effect of $\operatorname{Rg} 5$ on cholesterol biosynthesis metabolic pathway: Heatmap of gene expression (in fold changes compared to control, red, upregulation and green, downregulation), after exposure with ginsenoside Rg5 at different concentrations; the $100 \mu \mathrm{M}$ signature is shown in the leftmost column as solid red or green squares indicating genes that are upregulated or downregulated, respectively; color intensity indicates the actual log-fold changes.

\subsection{Predicted Effects of Ginsenoside Rg5}

\subsubsection{Molecular and Cellular Functions}

Figure 17 demonstrates that Ginsenoside $\operatorname{Rg} 5$ can have a significant impact on some of the cellular functions only at the highest concentration. On the contrary, at low concentrations, $\mathrm{Rg} 5$ has no impact on some other cellular functions at the highest concentration but exhibits a significant effect in low concentrations. Rg5 has a trend to inhibit the apoptosis of neuronal cells at a wide range of concentrations with the maximal impact at the concentration of 1 pM. Figure 18 demonstrates the molecular networks of deregulated genes that contribute to the inhibition of apoptosis at the concentration of $\operatorname{Rg} 51 \mathrm{pM}$ and the reversal effect at the toxic concentration of $100 \mu \mathrm{M}$.

\subsubsection{Physiological Functions}

Ginsenoside $\operatorname{Rg} 5$ can have a significant impact on some of the cellular functions only at the highest concentration, Figure 19. On the contrary, at low concentrations, Rg5 has no impact on some other cellular functions at the highest concentration but exhibits a significant effect in low concentrations.

\subsubsection{Diseases and Disorders}

Figure 20 shows that ginsenoside Rg5 can have a significant impact on some types of cancer and movement disorders both at low and high concentrations.

Molecular networks of deregulated genes that contribute to the movement disorders and cancer at the concentration of Rg5 $100 \mu \mathrm{M}$ and $1 \mathrm{aM}$ are sown in Figures 21 and 22. 


\section{Canonical pathways}

log(p-value)
Apoptosis
Invasion of cells
Cell death of stem cells
Apoptosis of stem cells
Accumulation of sphingolipid
Synthesis of lipid
Metabolism of membrane lipid derivative
Cellular homeostasis
Metabolism of acylglycerol
Recruitment of myeloid cells
Epithelial-mesenchymal transition
Cytokinesis
Cell cycle progression of lymphocytes

(a)

\section{Canonical pathways}

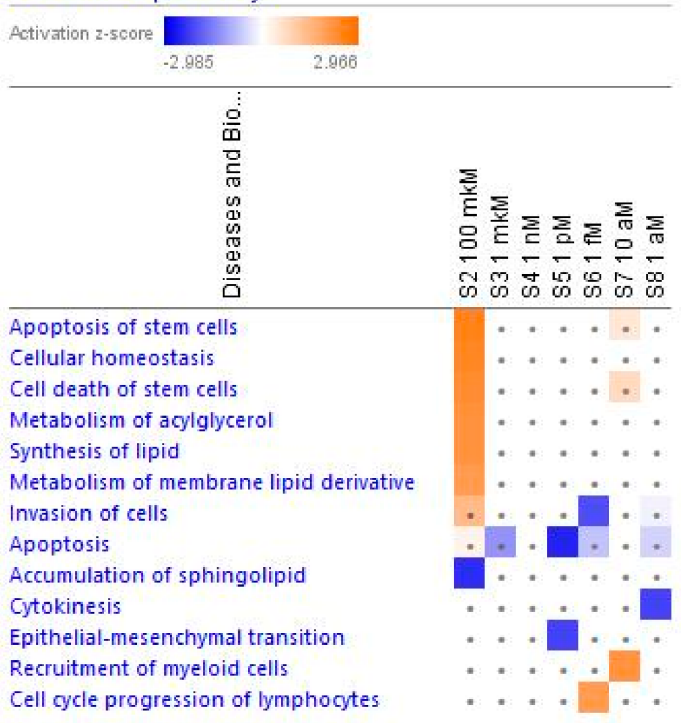

(b)

Figure 17. Effect of $\operatorname{Rg} 5$ at concentrations of $1 \mathrm{aM}, 10 \mathrm{aM}, 1 \mathrm{fM}, 1 \mathrm{pM}, 1 \mathrm{nM}, 1 \mu \mathrm{M}$ and $100 \mu \mathrm{M}$ ) on molecular and cellular functions (including apoptosis of neurons). (a) the brown color shows the predicted activation, blue color the predicted inhibition of signaling pathway; the symbol shows that the activation $z$-score was $<2$. (b) the symbol shows that the $-\log$ $p$-value was $<1.3$.

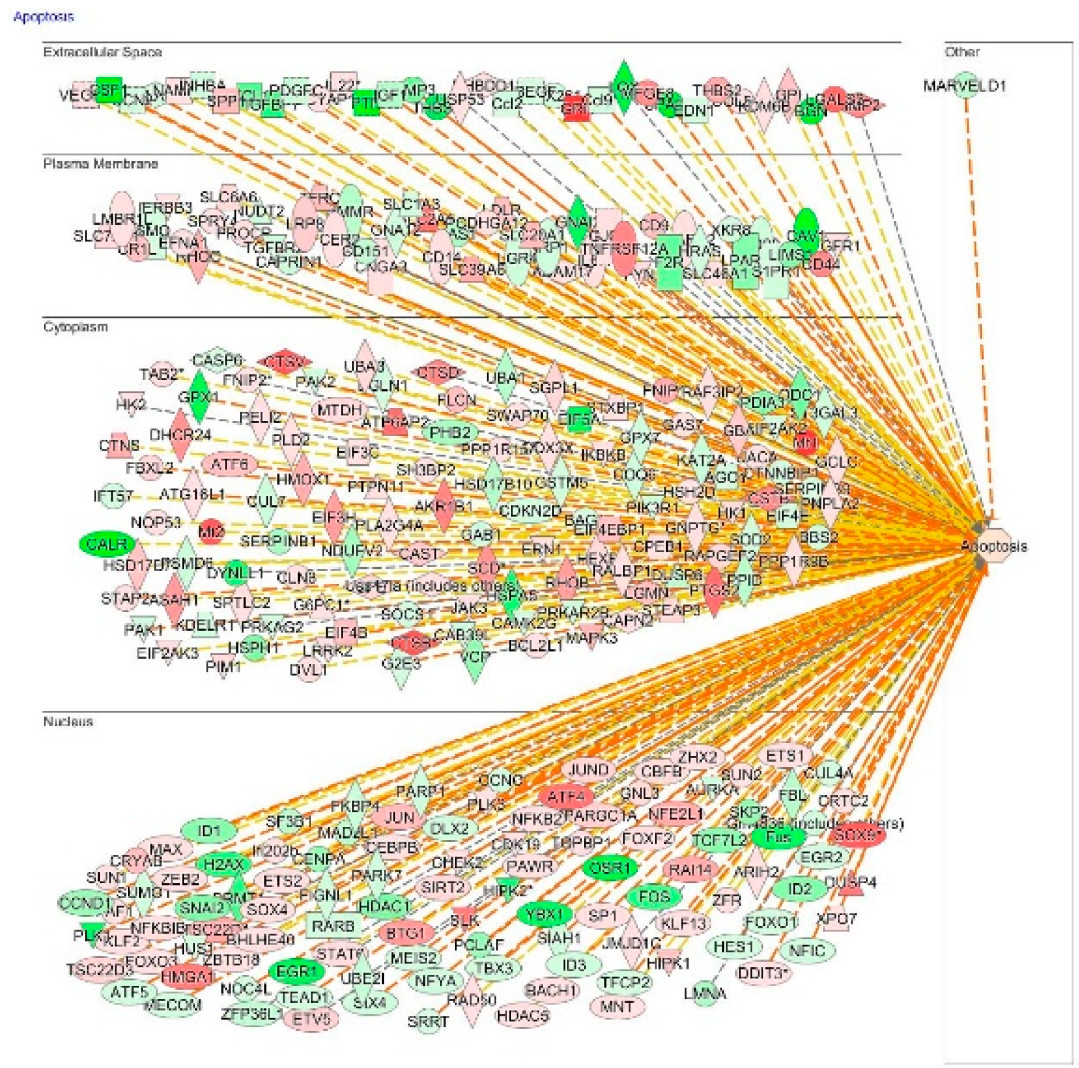

Figure 18. Cont. 


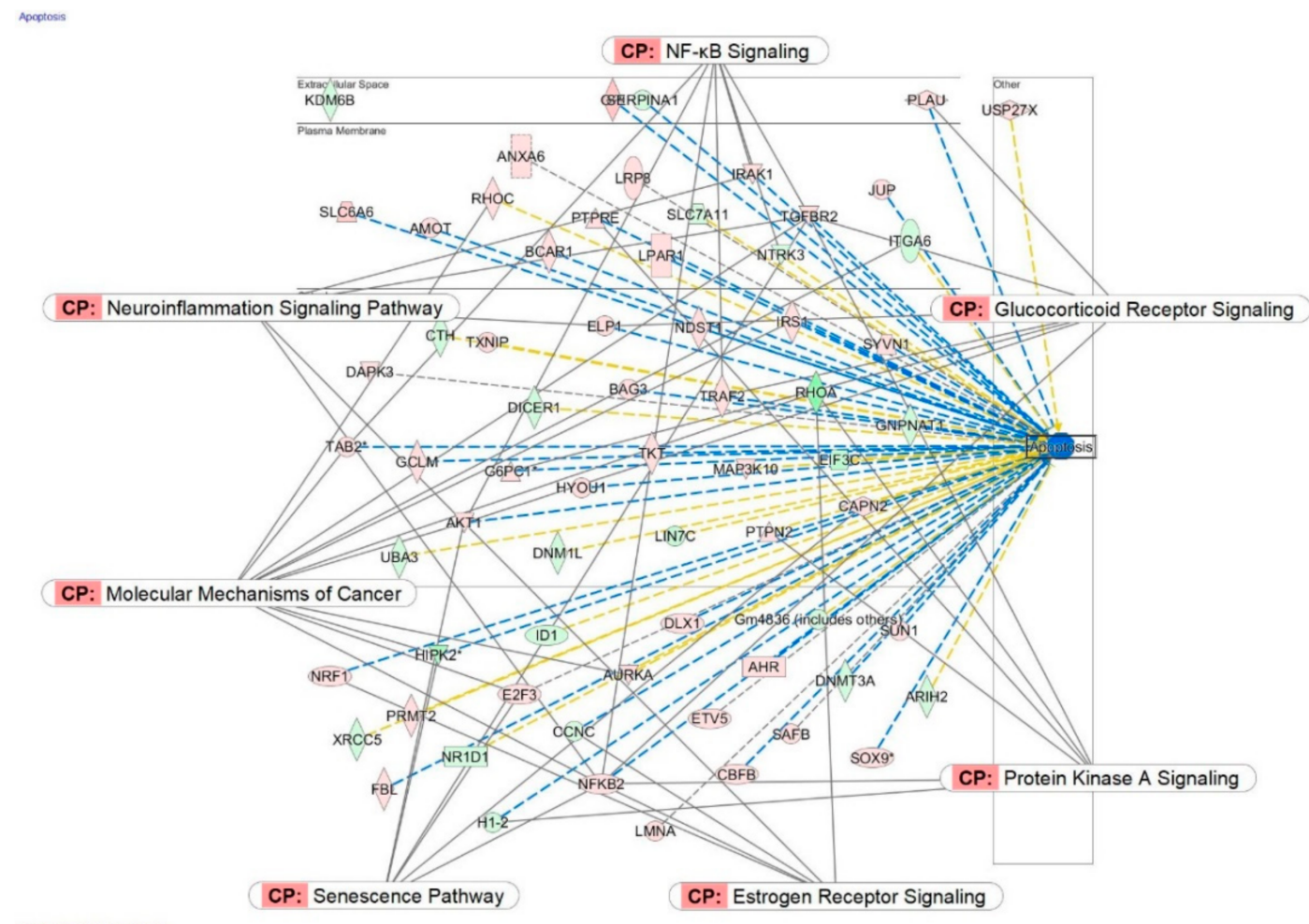

(b)

Figure 18. Predicted effects of Rg5 on apoptosis: (a) activation (brown) at a concentration of $100 \mu \mathrm{M}$; (b)—predicted inhibition (blue) at a concentration of $1 \mathrm{pM}$.

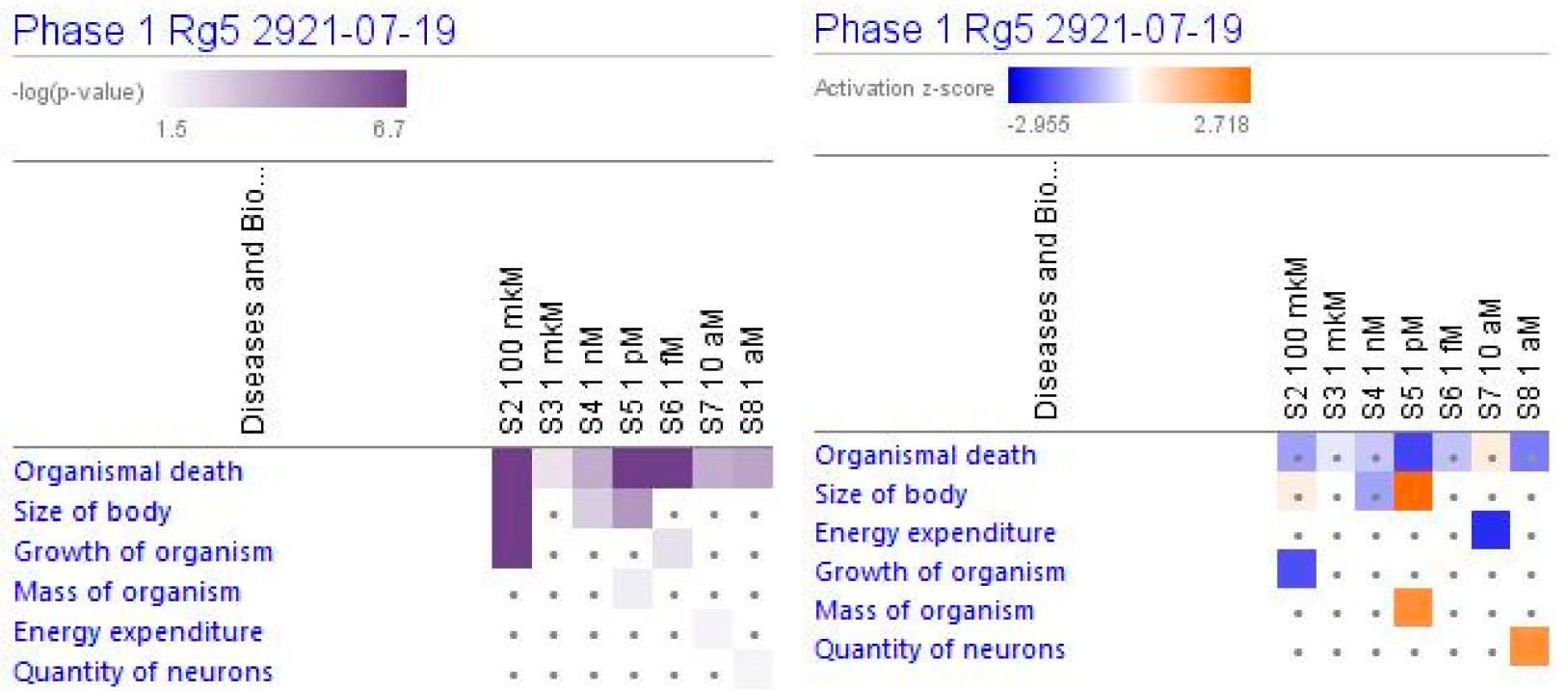

(a)

(b)

Figure 19. Effect of Rg5 at concentrations of $1 \mathrm{aM}, 10 \mathrm{aM}, 1 \mathrm{fM}, 1 \mathrm{pM}, 1 \mathrm{nM}, 1 \mu \mathrm{M}$ and $100 \mu \mathrm{M})$ on physiological functions, including organismal death. (a) The brown color shows the predicted activation, blue color the predicted inhibition of signaling pathway; the symbol shows that the activation z-score was $<2$. (b) The symbol shows that the $-\log p$-value was $<1.3$. 


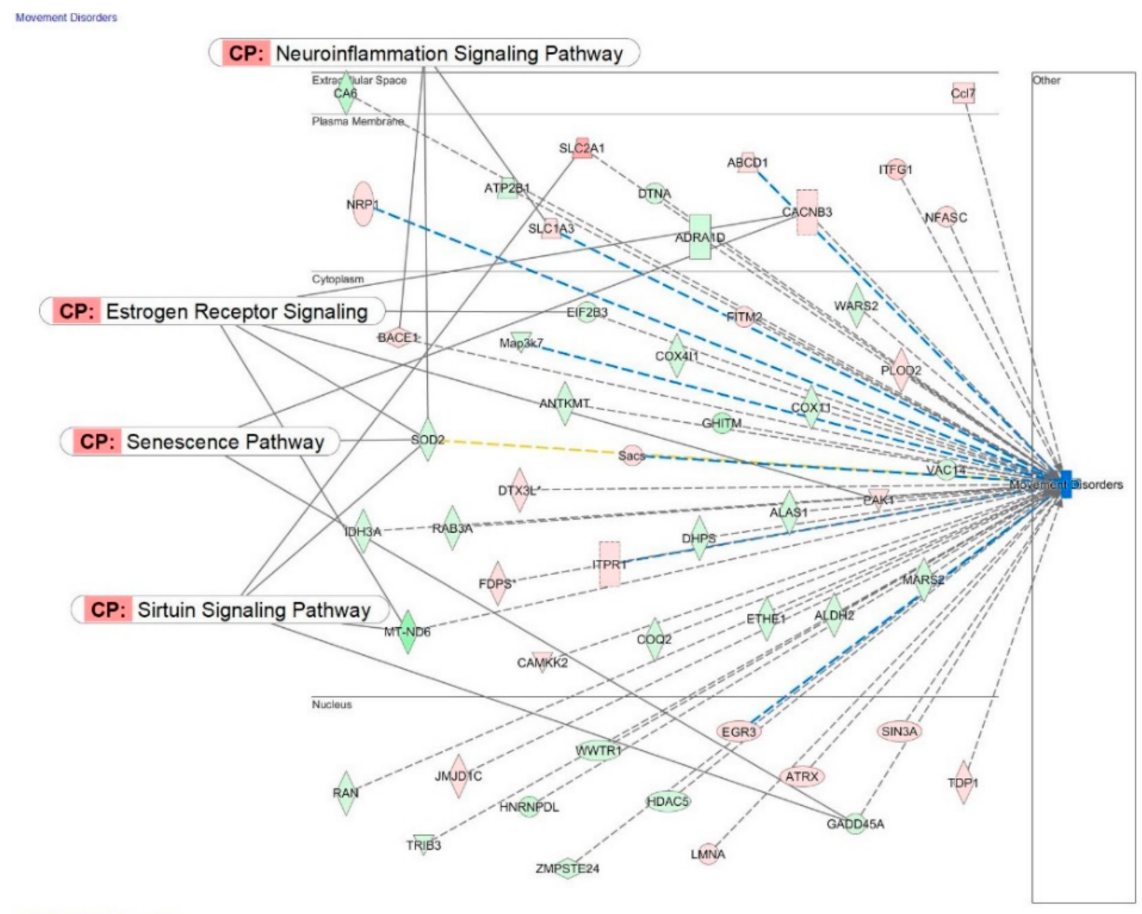

(b)

Figure 21. Predicted effects of Rg5 on movement disorders: (a) activation (brown) at a concentration of $100 \mu \mathrm{M}$; (b) predicted inhibition (blue) at a concentration of $1 \mathrm{aM}$.

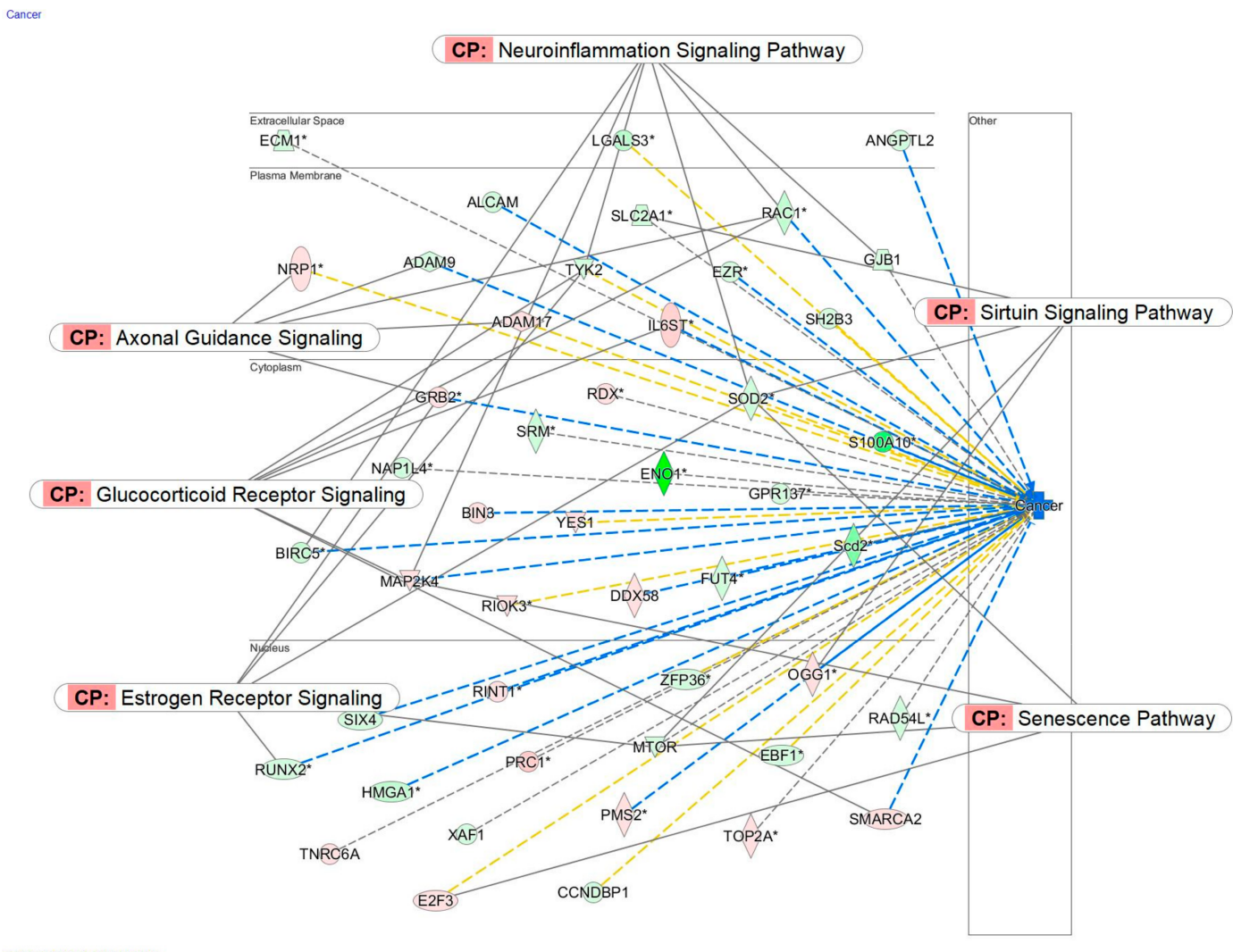

Figure 22. Predicted effects of Rg5 in cancer: predicted inhibition (blue) at the concentration of $100 \mathrm{nM}$. *: Results from Network Pharmacology of Red Ginseng (Part II). 


\section{Discussion}

Results of available pharmacological studies of ginsenoside Rg5 conducted in several in vitro (Supplemental Table S1 in Supplement 1) and in vivo (Supplemental Table S6 in Supplement 1) experimental animal models of neurological, inflammatory, metabolic disorders, and cancer have been recently reviewed [54]. It was concluded that ginsenoside $\mathrm{Rg} 5$ has the potential as an anticancer and anti-inflammatory drug, particularly in neurodegenerative diseases including mild cognitive impairments, Alzheimer's disease, Huntington's disease, and Parkinson's disease.

In all of these animal studies [16,32,34-36,39,43,55-58], ginsenoside $\operatorname{Rg} 5$ was active at a dose of $10 \mathrm{mg} / \mathrm{kg} \mathrm{BW}$, which corresponds to a human dose of $5 \mathrm{~g}$ Red Ginseng dry root containing 2\% Rg5 (Supplemental Table S6 in Supplement 1).

The maximal concentration of $\mathrm{Rg} 5$ in the blood of human subjects taking ginseng orally at a dose of $9 \mathrm{~g}$ was $2-10 \mathrm{nM}$ [44]. Ginsenoside $\mathrm{Rg} 5$ protected neuronal cells from glutamate-induced apoptosis in an in vitro Huntington's disease assay at a concentration of $1000 \mathrm{nM}$ [32] and exhibited a neuroprotective effect in heat stress-induced apoptosis at concentrations of 26-52 $\mu \mathrm{M}$ in experiments with murine hippocampal neuronal HT22 cells, but was toxic at concentrations of 78-104 $\mu \mathrm{M}$ [33]. In our study, ginsenoside Rg5 was pharmacologically active both at micro-molar and nano-molar concentrations as well as in a wide/broad range of physiological sub-physiological concentrations from picomolar $\left(10^{-12} \mathrm{M}\right)$ to act-molar $\left(10^{-18} \mathrm{M}\right)$, significantly changing the expression (in about $300-800-$ fold change) of almost the same number of genes (370 \pm 69 ; RSD $=18.53 \%)$ (Table 1, Figure 1). The broad range concentration-gene expression relationships were not linear for many genes. Some of them were reversed at the toxic concentration of $100 \mu \mathrm{M}$ (Figure $1 \mathrm{~b}$ ) if the number of Rg5 molecules was over $2 \times 10^{9}$ per one neuronal cell (Table 1 , Figure 1).

Considering that the blood level of ginsenoside $\operatorname{Rg} 5$ is not steady and varies over time during absorption and clearance for 24-72 $\mathrm{h}$ after repeated oral administration, the target cells of various tissues, including brain tissues, are continuously exposed to different doses/concentrations of ginsenoside Rg5. In this context, the difference in gene expression profiles to varying concentrations of Rg5 and predicted effects on signaling and metabolic pathways, molecular networks, cellular, physiological functions in various concentrations of $\operatorname{Rg} 5$ (Figures 2-22) was remarkable.

Notably, relatively few genes were deregulated at several low concentrations, and only one gene, $\mathrm{Ca} 6$, encoding the extracellular enzyme carbonic anhydrase 6 was regulated by ginsenoside $\mathrm{Rg} 5$ at all tested concentrations. Rg5 down-regulated $\mathrm{Ca} 6$ at all low concentrations (Figure $1 \mathrm{~b}$ ), suggesting that $\mathrm{Rg} 5$ acted like the antihypertensive Ca6 inhibitors acetazolamide and chlorothiazide [59,60].

Most deregulated genes were specific at every single concentration (concentrationspecific gene expression signatures) (Figures 6a, 7a, 8a, 9a, 10a, 11a, 12a, 13a, 14a and 16). This had an impact on the expected activation or inhibition signaling (Figures 2-14) and metabolic (Figure 15) canonical pathways, cellular (Figures 17 and 18), and physiological (Figure 19) functions, as well as organismal disorders and diseases (Figures 20-22) at various concentrations.

The IPA analyses of the datasets revealed that ginsenoside Rg5 has the potential to activate the biosynthesis of cholesterol (the precursor of all steroid hormones).

Furthermore, Rg5 exhibited predictable beneficial effects in senescence, neuroinflammation, apoptosis, organismal death, movement disorders, and cancer.

Typical features of all "low dose" effects compared to the "high dose" effects were somewhat soft-acting, which was characterized by considerably fewer genes involved in regulating signaling pathways and cellular physiological functions and disorders.

At first glance, some of the results were contradictory to those observed in other studies, where significantly higher (micromolar) concentrations (Supplementary Table S1 in Supplement 1) have been applied, which have no clinical significance simply since the corresponding human doses are far beyond the traditionally used (Supplementary 
Tables S1 and S4 in Supplement 1). For example, it was reported that ginsenoside Rg5 inhibits NF-kB signaling in macrophages, human epidermal keratinocytes, HeLa, A549, and 293T cancer cells at the concentration 20-50 $\mu \mathrm{M}$ [38-40] (Table S1 in Supplement 1), but in our study ginsenoside, Rg5 induces mild upregulation (53- to103-fold) of Nfkb2 gene expression both at low and highest concentrations (10 aM, $1 \mathrm{fM}, 1 \mathrm{pM}$, and $100 \mu \mathrm{M})$.

However, the key point is that the functional role of NF- $\mathrm{KB}$ in neurons is different from other cells $[61,62]$. In neurons, NF- $\mathrm{kB}$ signaling plays a role not only in neuroprotection, neurodegeneration, inflammation, and apoptosis but also in neuronal development, learning, memory, and synaptic plasticity [61-63]. Activation of constitutive NF- $\mathrm{KB}$ is involved in learning and memory processes via activation of PKA signaling molecules [62]. PKA activates P-CREB protein which leads to the release of neurotrophins in the neurons for learning and memory. The inhibition of NF- $\mathrm{kB}$ signaling resulted in behavior or memory deficits associated with suppression of CREB phosphorylation [64].

Activation of constituent $\mathrm{NF}-\mathrm{kB}$ can also prevent the death of neurons by inducing the production of anti-apoptotic proteins such as Bcl-2, IAPs, and manganese superoxide dismutase $[61,62]$. On the contrary, abnormal activation of inducible NF- $\kappa B$ triggers pro-apoptotic, pro-inflammatory genes encoding caspases and Bax, IL-12 and IL-17, and neurotoxic glutamate and iNOS, triggering further cellular damage [62]. In this context, mild the upregulation of expression of NF- $\mathrm{KB}$ is an adaptive (hormetic) stress response of neuronal cells $[53,61-66]$ to ginsenoside Rg5, which is typical for adaptogens increasing cell survival [67]. Furthermore, ginsenoside $\operatorname{Rg} 5$ activates CREB signaling pathway at four low concentrations ( $1 \mathrm{aM}, 1 \mathrm{fM}, 1 \mathrm{pM}, 1 \mu \mathrm{M})$ that is also in line with the mechanisms discussed above and predicted beneficial effects of ginsenoside $\operatorname{Rg} 5$ in neurodegeneration learning and memory.

There are several limitations of this study. One of them is the lack of scientific literature about the direction of correlations between gene expression and physiological function or disease that can be used in Silico analysis for predictions related to some findings in our experiments. The second limitation is related to the number of concentrations points in the dose-response correlation study: more intermediate points in the range of 1000 fold difference will show smooth changes from point to point. Other studies where different experimental outcome measures will be used are required. Finally, clinical studies in predicted diseases in human subjects are needed.

Overall, this is the first evidence of pharmacological activity of ginsenoside $\operatorname{Rg} 5$ in concentrations detected in human pharmacokinetic studies.

\section{Materials and Methods}

All materials and methods used in the present study have been described in detail in our previously published studies $[68,69]$. Therefore, only a short description of mRNA microarray hybridization, and Ingenuity pathway analysis (IPA) is provided below.

\section{1. mRNA Microarray Hybridization}

Murine hippocampal neuronal HT22 cells were seeded and attached for $24 \mathrm{~h}$ prior to drug treatment. Cells were then treated for $24 \mathrm{~h}$ at various combinations and concentrations of drugs or DMSO as solvent control $(0.5 \%)$. Total RNA was isolated using the InviTrap ${ }^{\circledR}$ Spin Universal RNA mini kit (250 preps; Stratec Molecular). RNA concentrations were determined using the NanoDrop spectrophotometer (NanoDrop Technologies, Wilmington, Delaware, DE, United States). The quality of total RNA was confirmed by gel analysis using the total RNA Nanochip assay on an Agilent 2100 bioanalyzer (Agilent Technologies, Santa Clara, CA, USA). Only samples with RNA index values $>8.5$ were selected for expression profiling. The experiments were performed in duplicate for treated samples and for control samples by the Genomics and Proteomics Core Facility at the German Cancer Research Center in Heidelberg, Germany. For mRNA microarray hybridization the Affymetrix GeneChips ${ }^{\circledR}$ with mouse Clariom S assays have been used according to the manufacturer's instructions. Data analysis was carry out by normalization of the signals using the quantile 
normalization algorithm without background subtraction, and differentially regulated genes were defined by calculating the standard deviation differences of a given probe in a one-by-one comparison of samples or groups. The data were further processed using Chipster software, version 4 (The Finnish IT Center for Science CSC).

\subsection{Ingenuity Pathway Analysis (IPA)}

Microarray data were analyzed by the Ingenuity Pathways Analysis (IPA) software, Summer release 2021 (QIAGEN Bioinformatics, Aarhus C, Denmark). Using IPA, we performed different predictive algorithmic calculations on transcriptomic datasets, resulting in varying analyses, including (i) canonical pathways, which displayed the molecules of interest within well-established signaling or metabolic pathways; and (ii) upstream analyses, which predicted the upstream regulators (any molecule that can influence the transcription or expression of another molecule) that might be activated or inhibited to explain the expression changes in test datasets.

The interpretation of gene expression data was facilitated by consideration of prior biologic knowledge. IPA software relies on the Ingenuity Knowledge Base, a frequently updated database containing biologic and chemical interactions and functional annotations with a large gathering of observations with more than 8.1 million findings manually curated from the biomedical literature or integrated from 45 third-party databases. The network contains 40,000 nodes that represent mammalian genes, molecules, and biologic functions. Nodes are linked by 1,480,000 edges representing experimentally observed cause-effect relationships that relate to gene expression, transcription, activation, molecular metabolism, and binding. Network edges are also associated with a direction (either activating or inhibiting) of the causal effect [70].

To obtain information about the impact of test samples on cellular signaling pathways and networks for biologic functions and diseases downstream of the genes, whose expression has been altered in a dataset, we used the IPA Core Analysis tool for all tested datasets. Analysis of transcriptomic data enabled us to predict regulators that are activated or inhibited based on the distinct up- and downregulation patterns of the expressed genes, and to determine which causal relationships previously reported in the literature are likely to be relevant for the biologic mechanisms underlying the data.

\subsection{Statistical Analysis}

Two statistical methods of analysis of gene expression data were used in Ingenuity Pathway analysis: (a) Gene-set-enrichment method, where differentially expressed genes are intersected with sets of genes that are associated with a particular biological function or pathway providing an 'enrichment' score [Fisher's exact test $p$-value] that measures overlap of observed and predicted regulated gene sets [71,72]; (b) The method that based on previously observed cause-effect relationships related to the direction of effects reported in the literature $[73,74]$ providing so-called z-scores assessing the match of observed and predicted up/down-regulation patterns [70]. The predicted (z-score $>2$, or $-\log$ FET $p$-value $>1.3$ ) effects are based on changes of gene expression in the experimental samples relative to the control.

\section{Conclusions}

For the first time, we have demonstrated that ginsenoside Rg5 exhibits soft-acting effects in a wide range of physiological concentrations and a strong reversal impact at the highest (toxic) concentrations on gene expression of neuronal cells.

Network pharmacology analyses of genes expression profiles using IPA software showed that ginsenoside Rg5 have the potential to activate the biosynthesis of cholesterol (the precursor of all steroid hormones), and to exhibit predictable effects in neuroinflammation, senescence, apoptosis, and immune response, suggesting soft-acting, beneficial impact on organismal death, movement disorders, and cancer (carcinoma, genitourinary tumor, solid malignant tumor, and sarcoma). 
Supplementary Materials: The following are available online at https:/ / www.mdpi.com/article / 10.3390 / ph14100999/s1, Supplementary data 1-11.

Author Contributions: S.A. contributed to the execution of experiments, data management, and manuscript preparation. T.E. contributed to the overall management of the study and manuscript preparation. A.P. contributed to the study conception, design and evaluation, data analysis, interpretation of the results, and drafting and preparation of the manuscript. All authors have read and agreed to the published version of the manuscript.

Funding: This work was funded in part by Europharma USA (Green Bay, WI, USA) and Botalys SA (Ath, Belgium). The sponsors of the research were Mr. Terrence Lemerond, Europharma USA Inc., USA; Botalys SA, Belgium; Paul-Evence Coppee, Botalys SA, Belgium (grant number 2019-03).

Institutional Review Board Statement: Not applicable.

Informed Consent Statement: Not applicable.

Data Availability Statement: Data is contained in the article and Supplementary Materials.

Acknowledgments: The author acknowledges the support of Botalys SA for the supply of investigational products and their characterization. Quality control was performed by Pierre-Antoine Mariage and Sylvie Defrère, Botalys SA, Belgium. We thank the Microarray Unit of the Genomics and Proteomics Core Facility, German Cancer Research Center (DKFZ), for providing excellent Expression Profiling services. The authors are grateful to Reiner Kunze (Institute of Physiology and Pathophysiology, Department of Medicine, Heidelberg University) for the generous gift of the murine neuronal cell line HT-22.

Conflicts of Interest: A.P. has an independent contractor agreement with EuroPharmaUSA Inc. All other authors declare no competing interests. The funders had no role in the design of the study; in the collection, analyses, or interpretation of data; in the writing of the manuscript, or in the decision to publish the results.

\section{References}

1. National Pharmacopoeia Committee. Pharmacopoeia of the People's Republic of China, English ed.; National Pharmacopoeia Committee: Beijing, China, 2010.

2. World Health Organization. Radix Ginseng. In WHO Monographs on Selected Medicinal Plants; World Health Organization: Geneva, Switzerland, 1999; Volume 1, pp. 168-182.

3. EMA/HMPC/321232/Assessment Report on Panax ginseng C.A. Meyer, Radix; Based on Article 16d (1), Article 16f and Article 16h of Directive 2001/83/EC as Amended (Traditional Use); European Medicines Agency: Amsterdam, The Netherlands, 2014.

4. EMA/HMPC/321232/Community Herbal Monograph on Panax Ginseng C.A. Meyer, Radix; European Medicines Agency: Amsterdam, The Netherlands, 2014.

5. Lee, S.M.; Bae, B.-S.; Park, H.-W.; Ahn, N.-G.; Cho, B.-G.; Cho, Y.-L.; Kwak, Y.-S. Characterization of Korean Red Ginseng (Panax ginseng Meyer): History, preparation method, and chemical composition. J. Ginseng Res. 2015, 39, 384-391. [CrossRef]

6. Bilia, A.R.; Bergonzi, M.C. The G115 standardized ginseng extract: An example for safety, efficacy, and quality of an herbal medicine. J. Ginseng Res. 2019, 44, 179-193. [CrossRef]

7. Hou, W.; Wang, Y.; Zheng, P.; Cui, R. Effects of Ginseng on Neurological Disorders. Front. Cell. Neurosci. 2020, 14, 55. [CrossRef]

8. Radad, K.; Gille, G.; Liu, L.; Rausch, W.-D. Use of Ginseng in Medicine with Emphasis on Neurodegenerative Disorders. J. Pharmacol. Sci. 2006, 100, 175-186. [CrossRef]

9. Leung, K.W.; Wong, A.S. Pharmacology of ginsenosides: A literature review. Chin. Med. 2010, 5, 20-27. [CrossRef]

10. Lee, S.; Rhee, D.K. Effects of ginseng on stress-related depression, anxiety, and the hypothalamic-pituitary-adrenal axis. J. Ginseng Res. 2017, 41, 589-594. [CrossRef]

11. Geng, J.; Dong, J.; Ni, H.; Lee, M.S.; Wu, T.; Jiang, K.; Wang, G.; Zhou, A.L.; Malouf, R. Ginseng for cognition. Cochrane Database Syst. Rev. 2010, 12, CD007769. [CrossRef]

12. Lee, M.S.; Yang, E.J.; Kim, J.I.; Ernst, E. Ginseng for cognitive function in Alzheimer's disease: A systematic review. J. Alzheimer Dis. 2009, 18, 339-344. [CrossRef]

13. Choi, J.; Kim, T.-H.; Choi, T.-Y.; Lee, M.S. Ginseng for Health Care: A Systematic Review of Randomized Controlled Trials in Korean Literature. PLoS ONE 2013, 8, e59978. [CrossRef]

14. Ong, W.-Y.; Farooqui, T.; Koh, H.-L.; Farooqui, A.A.; Ling, E.-A. Protective effects of ginseng on neurological disorders. Front. Aging Neurosci. 2015, 7, 129. [CrossRef]

15. Hallstrom, C.; Fulder, S.; Carruthers, M. Effects of Ginseng on the Performance of Nurses on Night Duty. Am. J. Chin. Med. 1978, 6, 277-282. [CrossRef] 
16. Kim, H.-G.; Cho, J.-H.; Yoo, S.-R.; Lee, J.-S.; Han, J.-M.; Lee, N.-H.; Ahn, Y.-C.; Son, C.-G. Antifatigue Effects of Panax ginseng C.A. Meyer: A Randomised, Double-Blind, Placebo-Controlled Trial. PLoS ONE 2013, 8, e61271. [CrossRef]

17. Arring, N.M.; Millstine, D.; Marks, L.A.; Nail, L.M. Ginseng as a treatment for fatigue: A systematic review. J. Altern. Complementary Med. 2018, 24, 624-633. [CrossRef]

18. Kaneko, H.; Nakanishi, K. Proof of the mysterious efficacy of Ginseng: Basic and clinical trials: Clinical effects of medical gin-seng, Korean Red Ginseng: Specifically, its anti-stress action for prevention of disease. J. Pharmacol. Sci. 2004, 95, 158-162. [CrossRef]

19. Mariage, P.-A.; Hovhannisyan, A.; Panossian, A.G. Efficacy of Panax ginseng Meyer Herbal Preparation HRG80 in Preventing and Mitigating Stress-Induced Failure of Cognitive Functions in Healthy Subjects: A Pilot, Randomized, Double-Blind, PlaceboControlled Crossover Trial. Pharmaceuticals 2020, 13, 57. [CrossRef]

20. Reay, J.L.; Kennedy, D.O.; Scholey, A.B. Effects of Panax ginseng, consumed with and without glucose, on blood glucose levels and cognitive performance during sustained 'mentally demanding' tasks. J. Psychopharmacol. 2006, 20, 771-781. [CrossRef]

21. Kennedy, D.O.; Scholey, A.B.; Wesnes, K.A. Dose dependent changes in cognitive performance and mood following acute administration of ginseng to healthy young volunteers. Nutr. Neurosci. 2001, 4, 295-310. [CrossRef]

22. Kennedy, D.O.; Reay, J.L.; Scholey, A.B. Effects of 8 weeks administration of Korean Panax ginseng extract on the mood and cognitive performance of healthy individuals. J. Ginseng Res. 2007, 31, 34-43.

23. Kennedy, D.; Scholey, A. Ginseng: Potential for the enhancement of cognitive performance and mood. Pharmacol. Biochem. Behav. 2003, 75, 687-700. [CrossRef]

24. Yeo, H.-B.; Yoon, H.-K.; Lee, H.-J.; Kang, S.-G.; Jung, K.-Y.; Kim, L. Effects of Korean Red Ginseng on Cognitive and Motor Function: A Double-blind, Randomized, Placebo-controlled Trial. J. Ginseng Res. 2012, 36, 190-197. [CrossRef] [PubMed]

25. Park, K.; Jin, H.; Rhee, H.Y.; Kim, S.; Lee, S.E.; Kim, Y.O.; Kim, G.S.; Kim, S.Y.; Yim, S.V.; Choi, Y.C. A randomized, dou-ble-blind, placebo-controlled clinical trial of Korean Ginseng as a functional food in mild cognitive impairment. Alzheimer Dement. 2013, 9, P804. [CrossRef]

26. Lee, S.-T.; Chu, K.; Sim, J.-Y.; Heo, J.-H.; Kim, M. Panax Ginseng Enhances Cognitive Performance in Alzheimer Disease. Alzheimer Dis. Assoc. Disord. 2008, 22, 222-226. [CrossRef] [PubMed]

27. Heo, J.H.; Lee, S.T.; Chu, K.; Oh, M.J.; Park, H.J.; Shim, J.Y.; Kim, M. An open-label trial of Korean red ginseng as an adjuvant treatment for cognitive impairment in patients with Alzheimer's disease. Eur. J. Neurol. 2008, 15, 865-868. [CrossRef]

28. Heo, J.H.; Lee, S.T.; Oh, M.J.; Park, H.J.; Shim, J.Y.; Chu, K.; Kim, M. Improvement of cognitive deficit in Alzheimer's disease patients by long term treatment with Korean red ginseng. J. Ginseng Res. 2011, 35, 457-461. [CrossRef] [PubMed]

29. Lemerond, T.; Panossian, A.G. Panax ginseng Meyer herbal pPreparation HRG80 for preventing and mitigating stress-induced failure of cognitive functions in healthy subjects. J. Altern. Complement. Integr. Med. 2020, 6, 100.

30. Dimpfel, W.; Mariage, P.-A.; Panossian, A. Effects of Red and White Ginseng Preparations on Electrical Activity of the Brain in Elderly Subjects: A Randomized, Double-Blind, Placebo-Controlled, Three-Armed Cross-Over Study. Pharmaceuticals 2021, 14, 182. [CrossRef]

31. Dimpfel, W.; Schombert, L.; Panossian, A.G. Panax ginseng preparations enhance long term potentiation in rat hippocampal slices by glutamatergic NMDA and kainate receptor mediated transmission. J. Altern. Complement. Integr. Med. 2020, 6, 106. [CrossRef]

32. Wu, J.; Jeong, H.K.; Bulin, S.E.; Kwon, S.W.; Park, J.H.; Bezprozvanny, I. Ginsenosides protect striatal neurons in a cellular model of Huntington's disease. J. Neurosci. Res. 2009, 87, 1904-1912. [CrossRef]

33. Choi, S.-Y.; Kim, K.-J.; Song, J.-H.; Lee, B.-Y. Ginsenoside Rg5 prevents apoptosis by modulating heme-oxygenase-1/nuclear factor E2-related factor 2 signaling and alters the expression of cognitive impairment-associated genes in thermal stress-exposed HT22 cells. J. Ginseng Res. 2017, 42, 225-228. [CrossRef]

34. Cho, Y.-L.; Hur, S.-M.; Kim, J.-Y.; Lee, D.-K.; Choe, J.; Won, M.-H.; Ha, K.-S.; Jeoung, D.; Han, S.; Ryoo, S.; et al. Specific Activation of Insulin-like Growth Factor-1 Receptor by Ginsenoside Rg5 Promotes Angiogenesis and Vasorelaxation. J. Biol. Chem. 2015, 290, 467-477. [CrossRef]

35. Yang, Y.-L.; Li, J.; Liu, K.; Zhang, L.; Liu, Q.; Liu, B.; Qi, L.-W. Ginsenoside Rg5 increases cardiomyocyte resistance to ischemic injury through regulation of mitochondrial hexokinase-II and dynamin-related protein. Cell Death Dis. 2017, 8, e2625. [CrossRef]

36. Kim, S.-J.; Kim, A.K. Anti-breast cancer activity of Fine Black ginseng (Panax ginseng Meyer) and ginsenoside Rg5. J. Ginseng Res. 2014, 39, 125-134. [CrossRef]

37. Liu, Y.; Fan, D. Ginsenoside Rg5 induces G2/M phase arrest, apoptosis and autophagy via regulating ROS-mediated MAPK pathways against human gastric cancer. Biochem. Pharmacol. 2019, 168, 285-304. [CrossRef]

38. Song, L.; Yang, F.; Wang, Z.; Yang, L.; Zhou, Y. Ginsenoside Rg5 inhibits cancer cell migration by inhibiting the nuclear fac-tor- $\mathrm{B}$ and erythropoietin-producing hepatocellular receptor A2 signaling pathways. Oncol. Lett. 2021, 21, 452. [CrossRef]

39. Kim, J.-E.; Lee, W.; Yang, S.; Cho, S.-H.; Baek, M.-C.; Song, G.-Y.; Bae, J.-S. Suppressive effects of rare ginsenosides, Rk1 and Rg5, on HMGB1-mediated septic responses. Food Chem. Toxicol. 2018, 124, 45-53. [CrossRef]

40. Ahn, S.; Siddiqi, M.H.; Aceituno, V.C.; Simu, S.Y.; Zhang, J.; Jimenez Pere, Z.E.; Kim, Y.J.; Yang, D.C. Ginsenoside Rg5:Rk1 attenuates TNF- $\alpha /$ IFN- $\gamma$-induced production of thymus- and activation-regulated chemokine (TARC/CCL17) and LPS-induced NO production via downregulation of NF-kB/p38 MAPK/STAT1 signaling in human keratinocytes and mac-rophages. Vitro Cell Dev Biol Anim. 2016, 52, 287-295. [CrossRef] 
41. Park, J.Y.; Choi, P.; Kim, T.; Ko, H.; Kim, H.K.; Kang, K.S.; Ham, J. Protective effects of processed ginseng and its active ginsenosides on cisplatin-induced nephrotoxicity: In vitro and in vivo studies. J. Agric. Food Chem. 2015, 63, 5964-5969. [CrossRef] [PubMed]

42. Liang, L.-D.; He, T.; Du, T.-W.; Fan, Y.-G.; Chen, D.-S.; Wang, Y. Ginsenoside-Rg5 induces apoptosis and DNA damage in human cervical cancer cells. Mol. Med. Rep. 2014, 11, 940-946. [CrossRef]

43. Cheng, Z.; Zhang, M.; Ling, C.; Zhu, Y.; Ren, H.; Hong, C.; Qin, J.; Liu, T.; Wang, J. Neuroprotective Effects of Ginsenosides against Cerebral Ischemia. Molecules 2019, 24, 1102. [CrossRef] [PubMed]

44. Yoo, S.; Park, B.-I.; Kim, D.-H.; Lee, S.; Lee, S.-H.; Shim, W.-S.; Seo, Y.; Kang, K.; Lee, K.-T.; Yim, S.-V.; et al. Ginsenoside Absorption Rate and Extent Enhancement of Black Ginseng (CJ EnerG) over Red Ginseng in Healthy Adults. Pharmaceutics 2021, 13, 487. [CrossRef] [PubMed]

45. Kim, H.K. Pharmacokinetics of ginsenoside Rb1 and its metabolite compound K after oral administration of Korean Red Gin-seng extract. J. Ginseng Res. 2013, 37, 451-456. [CrossRef]

46. Xu, Q.F.; Fang, X.L.; Chen, D.F. Pharmacokinetics and bioavailability of ginsenoside Rb1 and $\operatorname{Rg} 1$ from Panax notoginseng in rats J. Ethnopharmacol. 2003, 84, 187-192. [CrossRef]

47. Chen, S.; Xu, H.-Q.; Zhang, J.; Wang, C.-X.; Liu, J.-Q.; Peng, L.-H.; Cheng, J.-L.; Liu, A. A systematic study of the dissolution and relative bioavailability of four ginsenosides in the form of ultrafine granular powder, common powder and traditional pieces of Panax quinquefolius L, in vitro and in beagles. J. Ethnopharmacol. 2016, 185, 9-16. [CrossRef] [PubMed]

48. Zhou, Q.-L.; Zhu, D.-N.; Yang, Y.-F.; Xu, W.; Yang, X.-W. Simultaneous quantification of twenty-one ginsenosides and their three aglycones in rat plasma by a developed UFLC-MS/MS assay: Application to a pharmacokinetic study of red ginseng. J. Pharm. Biomed. Anal. 2017, 137, 1-12. [CrossRef]

49. Ma, C.; Lin, Q.; Xue, Y.; Ju, Z.; Deng, G.; Liu, W.; Sun, Y.; Guan, H.; Cheng, X.; Wang, C. Pharmacokinetic studies of gin-senosides Rk1 and Rg5 in rats by UFLC-MS/MS. Biomed. Chromatogr. 2021, 3, e5108.

50. Kim, H.; Lee, J.H.; Kim, J.E.; Kim, Y.S.; Ryu, C.H.; Lee, H.J.; Kim, H.M.; Jeon, H.; Won, H.J.; Lee, J.Y.; et al. Micro-/nano-sized delivery systems of ginsenosides for improved systemic bioavailability. J. Ginseng Res. 2018, 42, 361-369. [CrossRef]

51. Won, H.-J.; Kim, H.I.; Park, T.; Kim, H.; Jo, K.; Jeon, H.; Ha, S.J.; Hyun, J.M.; Jeong, A.; Kim, J.S.; et al. Non-clinical pharmacokinetic behavior of ginsenosides. J. Ginseng Res. 2018, 43, 354-360. [CrossRef]

52. Rosario, E.R.; Chang, L.; Head, E.H.; Stanczyk, F.Z.; Pike, C.J. Brain levels of sex steroid hormones in men and women during normal aging and in Alzheimer's disease. Neurobiol. Aging. 2011, 32, 604-613. [CrossRef]

53. Calabrese, E.J. Hormesis and ginseng: Ginseng mixtures and individual constituents commonly display hormesis dose re-sponses, especially for nNeuroprotective effects. Molecules 2020, 25, 2719. [CrossRef]

54. Liu, M.-Y.; Liu, F.; Gao, Y.-L.; Yin, J.-N.; Yan, W.-Q.; Liu, J.-G.; Li, H.-J. Pharmacological activities of ginsenoside Rg5 (Review). Exp. Ther. Med. 2021, 22, 1-9. [CrossRef]

55. Zhu, Y.; Zhu, C.; Yang, H.; Deng, J.; Fan, D. Protective effect of ginsenoside Rg5 against kidney injury via inhibition of NLRP3 inflammasome activation and the MAPK signaling pathway in high-fat diet/streptozotocin-induced diabetic mice. Pharmacol. Res. 2020, 155, 104746. [CrossRef]

56. Kim, E.-J.; Jung, I.-H.; Van Le, T.K.; Jeong, J.-J.; Kim, N.-J.; Kim, D.-H. Ginsenosides Rg5 and Rh3 protect scopolamine-induced memory deficits in mice. J. Ethnopharmacol. 2013, 146, 294-299. [CrossRef] [PubMed]

57. Chu, S.; Gu, J.; Feng, L.; Liu, J.; Zhang, M.; Jia, X.; Liu, M.; Yao, D. Ginsenoside Rg5 improves cognitive dysfunction and be-taamyloid deposition in STZ-induced memory impaired rats via attenuating neuroinflammatory responses. Int. Immunopharmacol. 2014, 19, 317-326. [CrossRef] [PubMed]

58. Xiao, N.; Yang, L.-L.; Yang, Y.-L.; Liu, L.-W.; Li, J.; Liu, B.; Liu, K.; Qi, L.-W.; Li, P. Ginsenoside Rg5 Inhibits Succinate-Associated Lipolysis in Adipose Tissue and Prevents Muscle Insulin Resistance. Front. Pharmacol. 2017, 8, 43. [CrossRef]

59. Farzam, K.; Abdullah, M. Acetazolamide. In StatPearls; StatPearls Publishing: Treasure Island, FL, USA, 2021.

60. Kountz, D.S.; Goldman, A.; Mikhail, J.; Ezer, M. Chlorthalidone: The Forgotten Diuretic. Postgrad. Med. 2012, 124, 60-66. [CrossRef] [PubMed]

61. Mattson, M.P.; Meffert, M.K. Roles for NF-kappaB in nerve cell survival, plasticity, and disease. Cell Death Differ. 2006, 13, 852-860. [CrossRef]

62. Stranahan, A.M.; Mattson, M.P. Recruiting adaptive cellular stress responses for successful brain ageing. Nat. Rev. Neurosci. 2012, 13, 209-216. [CrossRef]

63. Jha, N.K.; Jha, S.K.; Kar, R.; Nand, P.; Swati, K.; Goswami, V.K. Nuclear factor-kappa $\beta$ as a therapeutic target for Alzheimer's disease. J. Neurochem. 2019, 150, 113-137. [CrossRef]

64. Mattson, M.P.; Cheng, A. Neurohormetic phytochemicals: Low-dose toxins that induce adaptive neuronal stress responses. Trends Neurosci. 2006, 29, 632-639. [CrossRef]

65. Mattson, M.P.; Son, T.G.; Camandola, S. Viewpoint: Mechanisms of action and therapeutic potential of neurohormetic phytochemicals. Dose Response 2007, 5, 174-186. [CrossRef]

66. Mattson, M.P. Hormesis and disease resistance: Activation of cellular stress response pathways. Hum. Exp. Toxicol. 2008, 27, 155-162. [CrossRef] [PubMed] 
67. Panossian, A.G.; Efferth, T.; Shikov, A.N.; Pozharitskaya, O.N.; Kuchta, K.; Mukherjee, P.K.; Banerjee, S.; Heinrich, M.; Wu, W.; Guo, D.; et al. Evolution of the adaptogenic concept from traditional use to medical systems: Pharmacology of stress- and aging-related diseases. Med. Res. Rev. 2020, 41, 630-703. [CrossRef]

68. Seo, E.J.; Klauck, S.M.; Efferth, T.; Panossian, A. Adaptogens in chemobrain (Part I): Plant extracts attenuate cancer chemotherapy-induced cognitive impairment-Transcriptome-wide microarray profiles of neuroglia cells. Phytomedicine 2019, $55,80-91$. [CrossRef]

69. Panossian, A.; Seo, E.-J.; Klauck, S.M.; Efferth, T. Adaptogens in chemobrain (part IV): Adaptogenic plants prevent the chemotherapeutics-induced imbalance of redox homeostasis by modulation of expression of genes encoding Nrf2-mediated signaling proteins and antioxidant, metabolizing, detoxifying enzymes in neuroglia cells. Longhua Chin. Med. 2020, 3, 4. [CrossRef]

70. Krämer, A.; Green, J.; Pollard, J., Jr.; Tugendreich, S. Causal analysis approaches in Ingenuity Pathway Analysis. Bioinformatics 2014, 30, 523-530. [CrossRef] [PubMed]

71. Abatangelo, L.; Maglietta, R.; Distaso, A.; D’Addabbo, A.; Creanza, T.M.; Mukherjee, S.; Ancona, N. Comparative study of gene set enrichment methods. BMC Bioinform. 2009, 10, 275. [CrossRef]

72. Ihnatova, I.; Popovici, V.; Budinska, E. A critical comparison of topology-based pathway analysis methods. PLoS ONE 2018, 13, e0191154. [CrossRef]

73. Fakhry, C.T.; Choudhary, P.; Gutteridge, A.; Sidders, B.; Chen, P.; Ziemek, D.; Zarringhalam, K. Interpreting transcriptional changes using causal graphs: New methods and their practical utility on public networks. BMC Bioinform. 2016, 17, 1-15. [CrossRef]

74. Chindelevitch, L.; Ziemek, D.; Enayetallah, A.; Randhawa, R.; Sidders, B.; Brockel, C.; Huang, E.S. Causal reasoning on bio-logical networks: Interpreting transcriptional changes. Bioinformatics 2012, 28, 1114-1121. [CrossRef] [PubMed] 